\title{
Fiscal Policy in Macro Theory: A Survey and Evaluation
}

Karl Brunner

UNIVERSITY OF ROCHESTER

\section{Background}

Almost twenty years ago the "fiscalist issue" emerged as a major focus on macroeconomic debates. Milton Friedman and David Meiselman initiated the discussion with an article eventually published in the volumes of the "Monetary Commission." The debate was subsequently joined in the middle 1960s by Albert Ando, Michael De Prano, Donald Hester, Thomas Mayer, and Franco Modigliani. Jerry Jordan and Leonall Andersen, with other members of the research staff at the Federal Reserve Bank of St. Louis and their critics, continued the discussion toward the end of the 1960 s into the early years of the 1970 s.

Another round of discussions followed in the first half of the 1970s. The focus had somewhat changed, however. The Keynesian side acknowledged real effects of monetary influences, and the monetarists participating in the discussion recognized temporary real effects and permanent nominal effects of fiscal policy. Starting from this position, the contribution by Carl Christ (1968), Blinder and Solow (1974), Brunner (1976), and Brunner and Meltzer (1972a, 1972b, 1976) addressed mainly the feedback via the asset markets resulting from prevailing budgetary policies. This work reemphasized the idea of a "crowding out" of private capital formation associated with the financing of a budget deficit.

The appearance of "rational expectations" with the seminal work of Robert Barro, Robert Lucas, and Thomas Sargent modified our approach to monetary processes. It affected also the analysis of fiscal policy. The basic thrust provided by the prevailing formation of "rational expectations" encouraged the revival of an idea originally pondered by Ricardo. Rational expectations of agents expressing concern for future generations 
destroys the significance of financial decisions in the budget process. The financing of current expenditures with tax revenues or the sale of bonds yields the same results under the circumstances. Deficit finance determines future tax liabilities with a present value just matching the tax revenues currently suspended. Wealth, position, and opportunities of agents remain unchanged. Deficit finance affects, therefore, neither interest rates nor aggregate demand for output. This aspect of fiscal policy thus offers no wedge for influencing the aggregate evolution of the economy. This result contrasts both with Keynesian and inherited monetarist analysis. The ensuing discussions, however, uncovered processes linking tax policies (even lump sum policies) with real effects operating independently of direct portfolio and asset market effects. These processes are centered on intergenerational wealth transfers associated with debt and tax policies. The macroeconomic role of tax policies depends ultimately, so it appears, on the assumption of "intergenerational self-interest" or on specific risks and uncertainties.

An important role of tax policies apparently survives the emergence of rational expectations and so does a role for expenditure policies. Total expenditures and their structure still affect, in the context of this neoclassic analysis, consumption, investment, aggregate real demand for output, the supply of output, and real rates of interest. But the detailed nature of the mechanism differs radically from the Keynesian story. The government sector operates essentially as a production process absorbing products from the private sector as an input to produce an output. This output either competes with private consumption or contributes to the private sector's production process. This approach was originally suggested by Martin Bailey (1971) but disregarded by aggregate analysis. Both Keynesian and monetarist arguments treated "government" as a sinkhole swallowing a portion of private sector output. The emphasis on "government" as a production process operating with distortionary taxes changes the macroeconomic focus of fiscal policy in important ways.

The momentum of academic discussions substantially changed in retrospect the range of issues surrounding fiscal policy. The analytic evolutions and the resulting discussions modified many questions and emphasized new dimensions. Academic discussions were also influenced in recent years by political events and discussions in the public arena. The emergence of a comparatively large and possibly "permanent" deficit in the Federal budget motivated another round of discussions. There appeared voices claiming that such deficits produce, in contrast to Keynesian arguments, negative short-run effects on output. Others emphasized the long-run effects on normal growth. Many concentrated on linking high interest rates with the prevailing large deficit. The inflationary significance of the deficit was also considered. Some arguments seem to 
recognize a direct link between deficits and inflation. More carefully developed arguments emphasize the longer-run effect of persistent deficits on monetary policy. It would appear that an anti-inflationary policy pursued in the context of a permanent deficit cannot persist. Fiscal policy appears under the circumstances as the longer-run determinant of monetary policy and a crucial characteristic of the ultimately prevailing monetary regime. It follows that no reliable change in monetary regime is really feasible without an associated change in the long-run fiscal regime. This argument introduced a new focus and attention to fiscal policy.

The evolution of questions, issues, and analysis over the past nineteen years since the "war between the radio stations" (FM, AM, DM) in the American Economic Review (1965) justified in the judgment of the Conference organizers, and also in my judgment, an appraisal of our intellectual positions. My paper is addressed to this task. It offers essentially a survey over major strands of the discussion evolving over the past twenty years. This survey remains somewhat selective even within its confined range of macroeconomic issues. Neither does it cultivate a "neutral" account. It involves interpretations and evaluations referring to aspects of arguments advanced or to dimensions of the analysis that require more attention.

The first section covers the fiscalist-monetarist debate of the late sixties and early seventies. It evaluates the empirical work bearing on the central questions addressed at the time. The following section attends to the range of issues raised by the neoclassical cum rational expectations approach. Section 4 examines a number of problems recently associated with transitory and permanent deficits. The last section assesses the consequences of our intellectual position with respect to fiscal policymaking and the choice of fiscal regime.

\section{The Fiscalist Issue}

\subsection{The fiscalist-monetarist debate}

2.1.a. The evolving theme. The debate emerged gradually in the late 1950 s and was fully focused at the time of the conference on monetary theory organized by the National Bureau of Economic Research in Pittsburgh (1963). The intellectual state was conditioned at the time by the critical response of an increasing number of economists to the prevailing Keynesian analysis of fiscal and monetary policy. The core of Keynes's General Theory presents a real theory of a low-level output trap. It is supplemented by a real theory of business cycles. The central theme 
emphasizes the operation of two fundamental failures embedded in economic organizations relying on markets for the social coordination of activities. These market failures center on the stock market, as a guide for investment activities, and the labor market. They severely damage the ability of a market system to function as an instrument of social coordination. The peculiar characteristics of the stock market shape, so the story goes, a price behavior randomly related to the social function of rational resource allocation. These characteristics also suspend a reliable feedback from the saving-consumption nexus to an investment decision. Persistent mass unemployment suggested, moreover, to Keynes that potentially beneficial transactions remained suspended. Such potentialities are expressed by an excess of the labor suppliers' marginal utility of the wage product over the marginal disutility of labor. The market process apparently fails to provide a sufficient range of coordinating mechanisms.

These basic failures embedded in the structure of the economic process could not be offset by increased wage flexibility or monetary manipulations. Such endeavors would produce, at most, temporary deviations from the low-level output trap (Meltzer 1981). A more powerful instrument was required to move the economy out of such doldrums and push it nearer to full employment. Fiscal policy seemed to offer the instrumental opportunities needed for Keynes's purpose. The underlying analysis suggested that fiscal policy could be shaped to influence directly aggregate expenditures and to affect indirectly, via the multiplier, the level of consumption expenditures and total output and employment.

The message infiltrated the profession with some variations on the theme. Alvin Hansen's secular stagnation centered on the basic real phenomenon subsequently formalized by the "Keynesian cross." This formulation reenforced the "fiscalist thesis" emerging from the Keynesian analysis, a thesis that attributed dominant positive and normative significance to fiscal policy as an instrument conditioning the level of output and employment. Sir John Hicks's reinterpretation in terms of the IS/LM ("islamic") paradigm complicated the pattern somewhat with its inclusion of a feedback via asset markets and portfolio adjustments. But the assumption of accommodating monetary policy or the prevailing view attributing low-interest elasticity to aggregate demand and high-interest elasticity to money demand yielded a close approximation to the implications of the "Keynesian cross." The professional literature of the late forties and fifties reveals this state very clearly. The article on monetary policy by Seltzer (1945) in the late 1940s effectively reflects the dominant intellectual mood. The book Policies to Combat Depressions (1956) based on a conference organized by the National Bureau of Economic Research expresses the basic theme. It concentrated fully and only on fiscal policy. The slowly evolving flood of textbooks conveyed the same message and so 
did, to mention another example, Tinbergen's book On the Theory of Economic Policy (1952.)

The existing professional state must be clearly perceived in order to understand the subsequent intellectual developments. Doubts and reservations bearing on the central underlying theme of market failure never vanished entirely. The victorious sweep of the fiscalist thesis did not silence some expressions of doubt. Clark Warburton pursued the classic program of monetary analysis, offering a substantive alternative to the Keynesian vision. Milton Friedman (1952) reenforced the questioning with an examination of the comparative role of government expenditures and monetary movements in three wartime experiences. The classic research program rejected the market-failure approach introduced by Keynes as a serious misinterpretation of market economics and of specific events observed in the 1930s. Substantial doubts about the role assigned to fiscal policy by the Keynesian position was unavoidable under the circumstances. The evolution of monetarist ideas thus continues essentially a classical program. These ideas reject the dominance of fiscal policy as a determinant of both short- and long-run, aggregate, nominal or real demands. At least some strands of the analysis acknowledge an effect of fiscal policy on short- and long-term nominal demands, and a short-term effect on real demand for output, but they deny any effect on long-term aggregate real demand. However, all strands attribute to monetary shocks substantial short- and long-term nominal effects and a definite short-term real effect. This basic position was, however, sharpened with a specific "impulse hypothesis" incorporated into monetarist analysis. This position reversed the Keynesian thesis and assigned a comparatively dominant role to monetary impulses within the general pattern described above. This thesis of a comparative dominance was not advanced as an "ontological proposition." It was interpreted to reflect simultaneously the response characteristics of the economic mechanism and the historical circumstances expressed by the relative magnitude and variability of fiscal and monetary impulses. The dominant impulse hypothesis maintained by the monetarist was thus quite sensitively dependent on the choice of financial regime.

2.1.b. The empirical work. The professional state characterizing the earlier postwar period outlined in the previous paragraph needs to be fully appreciated in order to assess the empirical work initiated in the late 1950s by Milton Friedman and David Meiselman. This article motivated critical responses by Donald Hester (1964), Ando and Modigliani (1965), and De Prano and Mayer (1965). Another round of empirical discussion was unleashed by Leonall Andersen and Jerry Jordan (1968) with an article in the Review published by the Federal Reserve Bank of St. Louis. Other members (Michael Keran and Keith Carlson) of the St. Louis Fed's 
staff extended the discussion and so did Keynesian critics from the Board's staff in Washington (DeLeeuw and Kalchbrenner 1969) and the Brookings Institution (Goldfeld and Blinder 1972).

Harry Johnson (1971) asserted in the early 1970s that the empirical discussion of the $1960 \mathrm{~s}$ was fundamentally flawed and methodologically inadequate. Tobin (1981) recently repeated Johnson's assessment. The two authors thus convey an impression that little, if anything at all, can be learned from the first round of discussion about the role and significance of fiscal policy. Neither one of the authors, however, provides any references or offers any arguments or clues supporting their contention. The methodological objections raised at the time by Keynesians were apparently accepted at face value without further examination. It is noteworthy, therefore, that Keynesian critics justified their rather categorically formulated conclusions in terms of the same methodological procedure. An array of objections advanced with a categorical import frequently involved, moreover, nothing beyond invocations of possibly alternative, but unassessed, hypotheses. A retrospective appraisal from the vantage point of our current state of discussion may be useful for our purposes.

Consider first the basic purpose of the empirical work. It was addressed to a preliminary assessment of a wide and influential class of microeconomic hypotheses. An array of formulations filling textbooks and conveyed to the academic world with a sense of empirical relevance implied the dominant significance of fiscal policy and the irrelevance of monetary policy in shaping the evolution of output and nominal magnitudes. These implications were also mirrored by many policy statements supplied to the public arena. These broad statements about the nature of the economic process were the subject of a first round of searching investigation.

The examination, guided by the dominant underlying theme, essentially addressed a basic class of Keynesian theories. The class was determined by the specification of the income variable $y$, the autonomous expenditure variable $A$, and the linearity constraint. These specifications yielded the induced magnitude defined by $I=Y-A$ and the reduced forms $Y=\alpha+\beta A+\epsilon$ or $I=\gamma+\delta A+\nu$. A wide range of specific theories formulated with any given definition of $Y$ and $A$ yields the specific reduced forms. Changes in the definition of $Y$ and $A$ modify the relevant class under consideration. The dependence of the definition of $I$ on the definitions of $Y$ and $A$ is crucial in this context. This requirement was occasionally violated by some authors. This basic class was contrasted with a "quantity-theory" of the form $Y=a+b M+\mu$ or $I=c+d M+w$. The "simple" $K$-class implies that $\beta$ and $\delta$ are significantly positive, whereas $b$ and $d$ are zero. The "simple" version of the quantity-theory asserts the opposite. 
The investigation extended beyond the basic class of incomeexpenditure theories. They included classes defined by the reduced forms $Y=\alpha+\beta A+\gamma M+\epsilon$ or $I=a+b A+c M+\mu$. These formulations subsume all standard versions constructed in accordance with the "islamic" paradigm. The underlying theme to be assessed implies that $\beta$ dominates $\gamma$ (or $b$ dominates $c$ ) in significance.

The empirical assessment exploited both versions of the reduced form. The $I$-form offered a useful check on the $Y$-form. The latter produces a biased estimate of the $A$-coefficient due to the implicit correlations between $Y$ and $A$, which would yield an apparently significant coefficient estimate for $A$ even in the absence of any relevant systematic connection between $I$ and $A$.

A remarkable fact emerged once the investigation was under way. We seemed to have been conditioned to assume that we understood what Keynesian theory meant. But such understanding required that the profession agree on the specification of autonomous expenditures. The investigations, however, revealed a remarkable disarray and confusion. The critical comments advanced by Friedman and Meiselman $(1965,73)$ in this respect are still worth noting today:

We and our critics all used the same measures (for the money stock) without much ado. The contrast with 'autonomous expenditures' could hardly be sharper. Among us, we have produced more measures than there are critics. We settled on one; $A M$ on a different one, which is the sum of two separable components; DM, after running 'basic tests... on 20 different, but not unreasonable, definitions of autonomous expenditures' setthe on two, but also carry two others along for the ride; Hester came up with four measures that only partly overlap the others. And all of us harbor serious doubts about the measures we settled on. However useful 'autonomous expenditures' may be as a theoretical construct, it is still far from having any generally accepted empirical counterpart.

Another passage in Friedman and Meiselman's comments also deserves our current attention. It cautions against the potential evaluation of Keynesian theory by choosing larger portions of $Y$ and $A$ :

By our model, we in effect treated the income-expenditure theory as saying: if you know from other sources what is going to happen to roughly onetenth of $Y$ or $N$, then the multiplier analysis will tell you (or give you an estimate of what will happen to the other nine-tenths. AM converts the model into one that says: if you know from other sources what is going to happen to nearly half of $Y$ or over one-third of $N$, then the multiplier analysis will tell you what will happen to the other half of $Y$ or two-thirds of $N$. DM's two models treat only slightly less of total income as autonomous. If $\mathrm{AM}$ and $\mathrm{DM}$ were to continue along this line of 'improving' the 
model by having it predict a smaller and smaller percentage of income more and more accurately they would soon arrive at the point where it is predicting nothing-perfectly! In the old saw, with such friends, the income-expenditure theory hardly needs any enemies.

These issues found little attention at the time. They did reveal, however, that the sweep of Keynesian ideas, in spite of a vast literature and influential textbooks, had not been translated into a useful empirical theory. The strong assertions conveyed by the basic core of the incomeexpenditure approach, which frequently spilled over into categorical policy statements, were thus shown to have little substantive foundation.

2.1.c. The nature of objections and critique. An evaluation of the first-round discussion especially needs to consider the major objections advanced that possibly influenced Johnson's judgment, which was repeated by Tobin. Ando and Modigliani (1965), for instance, objected vehemently against the "single equation-single variable approach." They also criticized the use of "simple models" in lieu of "sophisticated models." Ando and Modigliani emphasized, in particular, at a later round of discussions that the regressions applied in the investigations under consideration were demonstrably inadequate to assess fiscalist propositions on the basis of observations controlled by a world conforming to a specific, large, econometric model (1976). Closely associated with these points was the accusation (or condemnation) that the procedure chosen reflected a "reduced form methodological commitment." This "simplistic" commitment was juxtaposed to the "sophistication" of a "structural" model. Authors were also inclined to criticize on grounds of "grievous misspecification." Ando and Modigliani, moreover, declared categorically that the examinations executed by Friedman and Meiselman are "basically irrelevant for the purpose of assessing the empirical uselessness of the income-expenditure framework." Disputes arose over the choice of exogenous variables. The other party's choices were naturally wrong, most particularly if one's own selection yielded approximately the desired estimate. Lastly, one author (Hester) asserted that "theory or intuition" was necessary to specify (correctly?) "the components of autonomous expenditures." This argument could, of course, be extended to the choice of exogenous variables.

These objections involve two important issues and reflect the confusions frequently emerging in the interpretation of the profession's empirical work. The first issue addressed by the critique emphasizes the "reduced form methodology," the "single-equation-single-variable" fallacy, or the propensity for simple, in lieu of, (more realistic?) "sophisticated" models. These objections essentially fail to recognize the rather specific and limited purpose of the investigations. This failure is especially visible in the quote drawn from the comments made by Ando and Modigliani. The 
"battery of tests" undertaken by Friedman and Meiselman and also the subsequent work contributed by the staff of the Federal Reserve Bank of St. Louis were not immediately directed to an assessment of the incomeexpenditure framework. A direct assessment of such a framework is logically impossible. Such assessments pertain to specific hypotheses or classes of hypotheses formulated in accordance with general criteria characterizing the framework. An assessment of the framework emerges ultimately from the cognitive fate of the hypotheses it generates. It would thus be clearly understood that none of the critical investigations was addressed to the framework. Previous passages emphasized that the assessment was directed at particular classes of hypotheses yielding strong propositions about the comparative significance of autonomous expenditures and at least potentially about fiscal policy. And once more, the prevalent intellectual state with its underlying theme fully justified this limited purpose-that is, limited relative to the general framework and its possible translation into classes of hypotheses.

The other three objections associated with the first issue involve different aspects or verbalizations of the same problem. The attribution of a methodological legislation insisting, as a matter of principle, on a reduced-form procedure reflects a pervasive misunderstanding about the logic of the procedure characterized above. The statements under examination pertaining to relative dominance of $A$ do not bear specifically on any particular structure; that is, they do not characterize or single out in a detailed fashion a particular hypothesis. They consistently describe a whole class of hypotheses and actually pertain to properties of the class. The most efficient procedure, under the circumstances, for systematic assessment of such statements uses the reduced form as a test statement. The properties of the reduced form reflect the properties of the class of hypotheses under examination. Structural estimation of a single member of the class is inefficient and essentially uninformative for the purpose. No methodological legislation is thus involved.

The use of a single equation with a single independent variable should now be clear. It was the appropriate choice for an assessment of the core class. It did not represent a single equation model or a disposition to favor simple, as against sophistical, models. The "single equation with single variable" was the appropriate choice for an evaluation of a class of hypotheses seriously presented in textbooks and class teachings. The objection thus either misses the point or really tells us that all the chapters and classes elaborating the Keynesian cross or widely used versions of the "islamic" framework should be clearly labeled as irrelevant pastimes without any use for the justificiation of any policy statements. This would also involve a major separation from Keynes, Hansen, and an influential literature controlling undergraduate teaching during the 1950s and in our hinterlands still today. 
A second issue embedded in the discussion bears on a pervasive confusion between logical issues and psychological effects. Our discussions frequently suffer under a disposition to reject an argument or hypothesis simply on the grounds that one is capable of formulating an alternative. Such ability offers, of course, no information about the cognitive status of the hypothesis under consideration. Objections adducing "misspecifications" are thus, by themselves, an empty gesture. They may be interpreted, however, as defining implicitly a program of further research. But the formulation of such a program possesses, by itself, no evidential value with respect to the initial hypothesis.

Some authors found that Friedman and Meiselman or Andersen and Jordan had committed some serious misspecifications. Ando and Modigliani developed, in particular, a "more sophisticated model" within the general "income-expenditure framework." They concluded from this construction that the evaluations made by Friedman and Meiselman were useless and irrelevant. We note first that the "laborious battery of tests" executed by Friedman and Meiselman and others is indeed irrelevant with respect to a wide class of hypotheses subsumable under the general income expenditure paradigm. This critique would be properly addressed to general conclusions about the role of fiscal policy drawn from the empirical work actually executed. Friedman and Meiselman and Andersen and Jordan carefully avoided such sweeping conclusions. Their evaluations were made relative to a specific class of "Keynesian-type" models and their significance is conditioned by this context. The evaluations would still be correct but irrelevant and useless if the class of hypotheses under consideration was demonstrably neglected, disregarded, and without any influence on the profession's policy thinking. But the latter condition hardly describes the professional situation of the earlier postwar period.

Hester's argument pertaining to the choice of autonomous magnitudes deserved special attention in this context: he suggested that theory or intuition determine this choice. But this choice determines the precise nature of the empirical theory. There exists no such theory involving a definite empirical context before this choice is made. The notion of a "theory" guiding the choice alluded to by Hester refers at best to formal structure linking variables with generic names. The admissible range of semantic rules connecting variables via measurement procedures with observations still includes many diverse possibilities. Whatever a priori notions of "preempirical theory" or intuition we exploit for the specification of crucial magnitudes yield, however, no evidence of the empirical validity of the choice is made. Neither Hester's notion of a "theory" nor any intuition can judge the empirically relevant choices. The suggestion fundamentally misconceives the nature of scientific pro- 
cedures and confuses the context of search for an hypothesis with the context of evaluation on the basis of critical observation.

2.l.d. The exogeneity issue. Hester's issue naturally generalizes to the specification of exogenous variables. Objections addressed to the selection or construction of exogenous magnitudes form a standard procedure of mutual criticism. But once again the execution of a set of regressions with more "desirable" coefficient patterns based on alternative choices of exogenous variables expresses a rival hypothesis but offers per se no relevant evidence discriminating between the alternative hypotheses. Reliance on the correlation coefficient must be carefully examined in these matters. Such reliance is quite appropriate for the evaluation of the core class addressed by Friedman and Meiselman. The hypothesis of comparative dominance implies systematic differences among correlation coefficients. We note in contrast that the eventual observation of higher correlation under alternative choices of monetary and fiscal variables possesses no evidential value discriminating between the selections. Such value can only exist relative to a specified class of hypotheses that implies statements about correlation patterns. This would require restriction on all the parameters, including a full description of stochastic properties under the alternative definitions. The observation of a comparatively high sample correlation and more "desirable" coefficient patterns under alternative exogeneity specifications in the absence of an initially formulated hypothesis therefore contains no discriminating cognitive significance. It forms at best the initial step in the formulation of an hypothesis still to be subsequently assessed against new data.

The exogeneity issue was further elaborated by Stephen M. Goldfeld and Alan S. Blinder (1972). The two authors explored in great and careful detail the implications of endogenous stabilization actions bearing on coefficient estimations in reduced forms. Their investigation is anchored by the reduced-form regressions used by Andersen and Jordan and expressed by Eq. (1). The symbols $F$ and $M$ refer to fiscal and monetary

$$
y=k+\alpha F+\beta M+\epsilon
$$

variables, and $\epsilon$ is a random term. It is, of course, well known that any correlation between $F$ and $M$ and $\epsilon$ as a result of an endogenous policy regime produces biased and inconsistent estimators of $\alpha$ and $\beta$. Goldfeld and Blinder pursue the matter well beyond this general statement and impose some structure on the nature of the correlations. This structure reflects a variety of assumptions about the nature of endogenous stabilization policies. The endogenous policy variables can be represented as a sum of a nonstochastic magnitude, which can be neglected for our purposes, and a stochastic term 


$$
F=\frac{\epsilon_{F}}{\alpha}, M=\frac{\epsilon_{M}}{\beta},
$$

where $\epsilon_{F}=\epsilon+u_{F}, \epsilon_{M}=\epsilon+u_{m}$, the variance of $\epsilon$ is $\sigma^{2}$, the variance of $u_{F}$ is $\gamma^{2} \sigma^{2}$ and the variance of $u_{M}$ is $\delta^{2} \sigma^{2}$. The $u$-terms reflect the forecasting ability of fiscal and monetary authorities exercised in the context of their stabilizing endeavors. The parameters $\gamma$ and $\delta$ represent the authorities' forecasting ability. Lower values of $\gamma$ and $\delta$ mean higher forecasting quality. Similar or coordinated forecasting may produce a correlation $\rho$ between $u_{F}$ and $u_{M}$. These assumptions imply the following probability limit for the ratios $\hat{\alpha} / \alpha$ and $\hat{\beta} / \beta$ of OLS estimates of the reduced form (1) to the true parameters

$$
\begin{gathered}
\frac{\hat{\alpha}}{\alpha}=1+\frac{\delta(\rho \alpha-\delta)}{\Delta}, \quad \frac{\hat{\beta}}{\beta}=1+\frac{\gamma(\rho \delta-\gamma)}{\Delta}, \\
\Delta=\gamma^{2}+\delta^{2}-\alpha \rho \gamma \delta+\gamma^{2} \delta^{2}\left(1-\rho^{2}\right)>0 .
\end{gathered}
$$

The three forecasting parameters associated with endogenous policy reactions clearly determine the outcome. Almost any combination of biases can be produced by shifting patterns of $\rho, \gamma$, and $\delta$. With $\rho=0, \delta$ large, and $\gamma$ small, fiscal policy may appear to be insignificant in reduced-form regressions of Eq. (1). An excellent stabilization record of the fiscal authorities supplemented with a poor record of monetary authorities could explain the Andersen-Jordan results even against the background of a substantial $\alpha$-coefficient.

The authors' general result is confirmed by elaborations of the argument. These elaborations include erroneous assumptions about the multipliers made by the authorities and lagged policy responses to serially correlated $\epsilon$-disturbances. They extend to the case of "policy interaction" where one authority's response takes into account the other agency's behavior. The argument also covers a more general model with exogenous variables added to Eq. (1). All these cases enlarge the range for potential bias beyond the initial parameters $\rho, \gamma, \delta$.

Goldfeld and Blinder supplement their analytic investigation of statistical implications associated with endogenous policy responses with a Monte Carlo study. They use an econometric model originally published by Moroney and Mason to generate data sets on the variables incorporated. These data sets were applied to structural and reduced-form estimations. Structural estimations proceeded with and without inclusion of reaction functions describing the policymakers' endogenous responses. It would appear that structural estimates are comparatively little affected by nonrecognition of endogenous policy responses. Direct estimation of 
the system's (exclusive of reaction functions) reduced form produces, in contrast, seriously biased multiplier estimates.

We should hardly quibble with the correctness of the argument advanced by Goldfeld and Blinder. Endogenous policy responses can yield seriously biased estimates of reduced forms exemplified by Eq. (1). The meaning of this result must be carefully assessed, however. The authors usefully sharpen our awareness for some important qualifications applicable to the empirical work which emerged in the context of the "fiscalist debate." The results hold for classes of hypotheses recognizing an actual state of comparative exogeneity with respect to policy variables. Goldfeld and Blinder offer no argument or evidence bearing on the crucial issues of whether, when and how "policy was endogenous." The correctness of their analysis does not, unfortunately, establish its relevance. We still need to judge the occurrence and nature of endogenous policy responses. It is important to understand, however, that judgments based purely on standard regression analyses can seriously mislead us. We also need to examine carefully the institutional arrangements and explore special events in the manner of Friedman and Schwartz (1963). Institutional information may often tell us what regressions, if any, are advisable. A "mechanical" linking of policy variables with a GNP gap hardly conforms to institutional situations prevailing over most periods or in most countries. The data used in regression estimates of Eq. (1) by various researchers covered a variety of historical episodes and also different countries. One would conjecture that the existing institutional differences generate widely different endogenous responses. A consistent pattern of statistical results over periods and countries deserve more serious considerations under the circumstances, even with full acknowledgment of the argument advanced by Goldfeld and Blinder. It is very doubtful for instance that past episodes of U.S. fiscal and monetary history exhibit a pronounced and approximately uniform stabilization policy. The available information about the Fed's strategy and tactical procedure suggests, moreover, the operation of a major random process affecting monetary growth over quarterly periods. This situation may, for all practical purposes, amount to an approximate exogeneity actually emphasized by Goldfeld and Blinder. The political economy of fiscal policy also suggests substantial doubts about the relevant occurrence of an endogenous fixed stabilization policy. "Stabilization" may be a useful rhetoric device addressed to academics and the public arena. But fiscal policy is dominated by other considerations associated with the incentive structure characterizing the existing policy institutions. This incentive structure implies that "fiscal policy" is dominated by redistributional interests with little substantive attention to "stabilization" per se. We should expect under the circumstances that regressions expressing fiscal 
reaction functions remain poorly defined and unstable over time. We may, of course, encounter situations justifying a substantial suspicion that endogenous policy responses do occur. But the implications with respect to estimates of Eq. (1) are obscure until we know more about the nature of endogenous policy patterns. Information about occurrence only establishes that we need be cautious in interpreting the results. But Goldfeld and Blinder still enriched our discussion. This contribution warms us essentially to extend the empirical work to as many different periods and situations involving different institutional arrangements as possible. This research strategy seems more promising than an approach relying on explicit statistical reaction functions of the usual kind embedded in a large structural model.

2.l.e. Some problems of statistical theory. A retrospective evaluation guided by an interest to learn from the previous discussions for our present purposes cannot avoid an application of standards-criteria of procedures developed subsequent to the discussion under examination. Two aspects bearing on statistical procedures and matters of statistical theory require our attention. Most of the discussants used level data; Ando and Modigliani and De Prano and Mayer used data only in this form. Friedman and Meiselman also explored first differences, whereas Andersen and Jordan only used first differences. The proper choice between these alternative procedures poses a subtle but very important and widely neglected issue even today. The choice depends sensitively on the error structure in the formulated regression (Plosser and Schwert 1978) or the nonstationarity of the variables (Meese and Singleton 1982). Plosser and Schwert compared the problems posed by over- and under-differencing of data in regression analysis. They explore, in particular, the asymmetric effect of over- and under-differencing on statistical inferences. They show that over-differencing produces a regression with an error term controlled by an $M A(1)$ process with a unit coefficient, whereas under-differencing yields a regression with a nonstationary random term. Over-differencing still allows, under the circumstances, reliable estimation and inferences. Under-differencing, in contrast, poses a serious problem. The sample distribution of the estimator does not possess finite moments. No inferences are possible in this case.

The authors elaborate the general problem with the aid of several examples bearing quite directly on our issue. The first example explores a regression $\log y=\alpha+\beta \log m+\epsilon$, with $y$ representing nominal income and $m$ the money stock. The regression is estimated in level form, in levels modified with a time trend, with Cochrane-Orcutt adjustment, and also in first and second differences. The last four procedures yield essentially the same estimate for $\beta$. The first estimate derived from level data is separated by more than two standard errors from the estimate obtained 
on the basis of first differences. Most interesting is a comparison of the variances computed for the error term in the regressions. Overdifferencing would imply that the variance associated with the first difference is twice the variance of the residual in the level regression. Under-differencing implies, in contrast, that the residual variance in the level regression exceeds the corresponding variance in the first difference. This implication is confirmed by the estimates.

The authors contrast this case with the "quantity theory of sunspots" expressed by the regression $\log y=\alpha+\beta \log s+\epsilon$, where $s$ measures the accumulated sum of sunspots. The same five estimation procedures, previously mentioned were carried out. The results based on level data convey the impressicn of a significant relation with a substantial correlation and a unit multiplier. The first difference yields a radically different result. The "multiplier" $\beta$-coefficient collapses to nonsignificance with a standard error almost equal to the coefficient estimate. The estimate derived from the second difference collapses even further and is hardly distinguishable from zero. The residual variance in the level regression is, moreover, almost 13 times the residual variance in first differences.

Lastly, the authors examine the data ( $A$ and $M$-in logs, however) used by Friedman and Meiselman. They compare the regressions $\log C=$ $\alpha+\beta \log M+\epsilon$ with $\log C=\gamma+\delta \log A+\partial$. The results are remarkably different. The five estimation procedures yield the same results for $\beta$. The differences are not statistically significant when evaluated in terms of the standard error of $\beta$ computed from first differences. Once again the residual variance of the level regression substantially exceeds this variance of the first differences. This pattern of residual variances occurs even more emphatically in the case of autonomous expenditures. The contrast offered by this regression appears, however, most particularly in the pattern of $\delta$-estimates associated with the five estimation procedures. The coefficient collapses from 1.08 in level data to 0.14 in first differences and 0.09 in second differences. The differences in estimates are statistically highly significant. All estimates remain, however, significantly different from zero.

This analysis with the examples immediately related to our problem clearly reveals the danger associated with under-differencing and the misleading inferences obtainable under these circumstances. The results developed by Plosser and Schwert suggest a definite strategy for empirical investigations, at least in our range of problems. In the usual absence of sufficient information about the error structure we need to estimate both in terms of level data (unadjusted and adjusted for possible serial correlation in residuals), first differences, and, possibly, even second differences. The resulting pattern of residual variances and coefficient estimates determines our evaluation. A residual variance of level regressions substan- 
tially higher than the corresponding variance associated with first differences suggests the relevant application of first differences. The regression obtained from level data should, moreover, be considered seriously suspect whenever the estimated regression coefficients substantially collapse for first and second differences. It follows thus that the results presented by Ando and Modigliani or De Prano and Mayer yield little information until further reevaluation.

A possibly more basic problem was raised by Meese and Singleton (1982) and Wasserfallen (1985). The standard assumptions for regression analysis are satisfied for stationary stochastic variables and nonstochastic independent variables. The latter case hardly applies to a relevant analysis of data cast up by social processes. But nonstationary stochastic data pose a serious problem for estimation and inferences. It would appear that consistent estimates of a regression require that the diagonal terms of the covariance matrix of independent exogenous variables converge to infinity with the sample size. Alternatively, it seems sufficient that the independent (and exogenous) vector variable be controlled by a finite autoregressive process. These conditions offer, however, no basis for inferences. More structure must be imposed in order to derive an asymptotic sampling distribution. The weakest condition on the moment matrix of independent variables seems to have been formulated, according to Meese and Singleton, by Grenander (1954): "These conditions preclude exponential growth of any variable.... Borderline non-stationarity (i.e., unit root) is allowed if regressors are fixed or strictly exogenous." Meese and Singleton emphasize that an independent error with finite variance is not a sufficient condition for asymptotic inferences. Quite generally, conditions on the regressors required for deriving inferences pose a troublesome issue. In the absence of good grounds supporting the relevant application of asymptotic distribution theory to inferences derived from nonstationary data, we may possibly obtain estimates but no judgment on evaluation. This argument reenforces the conclusion obtained from Plosser and Schwert's investigation: It seems advisable in the case of nonstationary data to derive the inferences from suitable transformation into stationary series. The neglect of this problem lowers the relevance of some empirical work presented in the "fiscalist" debate.

2.1.f. Some general conditions. We should emphasize first that Johnson's indictment, recently repeated by Tobin after more than ten years, simply has no foundation. It reflects a somewhat casual misunderstanding of the nature of the argument. Friedman and Meiselman explicitly cautioned the reader that this assessment was quite provisional. It was also a definitely limited examination, and so was the work undertaken at the Federal Reserve Bank of St. Louis. The limitation is defined by the class of hypotheses implicitly addressed by the tests used. There do exist 
classes of hypotheses that cannot be subsumed under the assessments carried out. Friedman and Meiselman properly stressed therefore that their results are "not decisive." They are certainly not decisive with respect to the general paradigm and the general idea of fiscal effects on aggregate demand. But the tests were properly formulated and executed relative to the class of hypotheses considered. A reservation should be entered, however, with respect to the use of under-differenced and nonstationary variables. We should also note the reservation advanced by Goldfeld and Blinder. This reservation simply suggests some further examination in order to take account of potential effects of endogenous policy reactions.

The discussion also brought forth a perennial problem confronting our empirical work. The choice of exogenous variables forms an important component in the construction of a hypothesis (or class of hypotheses). The development of statistical analysis has sharpened somewhat our understanding and offered approaches to this issue. One lesson we should emphatically learn in this context emphasizes that we need to address more careful attention to the admissible interpretation of our work. Our imaginative invention of alternative specifications or constructions of exogenous magnitudes offers per se no rational grounds for the rejection of other specifications and choices. We need either (more or less) direct evidence bearing on the exogeneity of the variables concerned or to depend on the evaluation of the hypothesis as a whole. Correlation statements may appear as relevant test statements in this context, provided, however, as in the case of the core class examined by Friedman and Meiselman, the hypothesis under consideration implies comparative correlation statements. Comparison of correlations in the absence of such definite implications is meaningless and without any evidential value.

The substantive content of the discussion contributed in retrospect to some clarification. The hard Keynesian position dismissing monetary conditions was unanimously discarded. The relevance of monetary conditions became generally recognized. Substantial issues remained, however, in this range. Some Keynesians argued that the money stock or monetary growth exerts "permanent" (long-lasting) real effects. Monetarists confine, in contrast, (temporary) real effects to monetary acceleration (or decelerations). More important for our immediate purpose was the general recognition that fiscal policy did probably modify to some extent nominal aggregate demand for output. Substantial differences concerning orders of magnitude and persistence of real effects remained.

There occurred also a subtle but interesting shift within the Keynesian paradigm. This shift modified the meaning of "fiscal dominance." We observe well into the 1950s an argument assigning a steep slope to the IS curve and a flat slope to the LM curve. This assignment was justified in terms of a borrowing-cost interpretation for the interest elasticity of aggre- 
gate demand (Brunner 1971). There clearly emerged a revision of this position during the 1960s. The relative slopes shifted sufficiently to offer monetary conditions a significant leverage. The inherited sense of "fiscal dominance" unavoidably disappeared. The appearance of the assignment problem and the policy mix analysis reveals this change. But the modified Keynesian analysis produced a new sense of "fiscal dominance" visible in the "Economic Reports" of the Kennedy-Johnson administration. Both monetary and fiscal policies were recognized to influence real magnitudes. Both policies were thus in principle applicable to stabilization purposes. Monetary policy was, however, judged to concentrate the social cost of stabilization policies on a small segment of the economy (housing). Fiscal policy, in contrast, spread these costs more "equitably." Fiscal policy was also judged to operate "directly," in contrast to the "indirect" effects of monetary policy; and, consequently, with shorter lags. These considerations determined that fiscal policy was proposed as the active component of a stabilization program with monetary policy assigned an essentially accommodating role defined in terms of an interest-rate strategy. This position was sensitively conditioned by the underlying paradigm summarized by the IS/LM approach and its economic interpretation. This paradigm with its confining view about the nature of the "transmission mechanism" remained, of course, on center stage in the dispute between "Keynesians" and "monetarists."

\subsection{The asset market effects of fiscal policy and the stability of the system}

The discussion covered in the previous paragraphs addressed the comparatively immediate output-market effects of fiscal policy. Neither Keynesians nor monetarists had at this stage integrated the ramifications of deficit financing via asset-market responses explicitly into their analysis. Attention focused by the early 1970 s on the government's budget constraint. The relation between fiscal policy and asset-market responses generated by the mode of deficit financing and the resulting interaction between asset markets and output markets became the subject of further examination (Christ 1979; Silber 1970; Blinder and Solow 1974, 1976; Infante and Stein 1976; Brunner and Meltzer 1972b, 1976; McCallum 1981). The participants in this discussion agreed that fiscal policy (including especially the effects of distortionary taxes and the structure of expenditures) affects actual output, normal output, price level, and real rates of interest. There remained, however, substantial variations in the details of the analysis and probably the order of magnitudes involved. The question pursued was addressed to the real and nominal consequences implicit in fiscal decisions beyond the effects attributable to (global) expenditures and taxes per se. 
My summary of the issue exploits a scheme used in various papers by Brunner and Meltzer. The scheme involves an interaction between four lines represented in Figure 3.1. The vertical line describes normal output. Some strands of analysis recognized the dependence of the line's position on taxes and most particularly on longer-run portfolio adjustments between government securities and real capital. The bbe line represents the balanced budget equation. It describes thus the locus of price level and output combinations $(p, y)$ that satisfy a balanced budget. The position of the line depends on real government expenditures, the stock of outstanding debt held by the public, and a tax parameter. The slope of the line expresses the nonhomogeneity of the deficit function due to progressive taxation, yielding a "bracket creep." Under proportional taxation the bbe line would be vertical. The $d$-line presents a pseudodemand curve to be understood in a semireduced sense. The line summarizes the locus of all pairs $(p, y)$ that satisfy simultaneously, for any given set of other variables, output- and asset-market equations. Lastly, the $s$-line describes the "structural" supply function. The position of this line moves with the expected price level, the stock of real capital, and technological progress.

The initial position in the diagram shows a state of full stock and normal output equilibrium. The short-run flow equilibrium determined by the interaction between pseudodemand and supply yields a state on the normal output line that simultaneously produces a balanced budget. Now

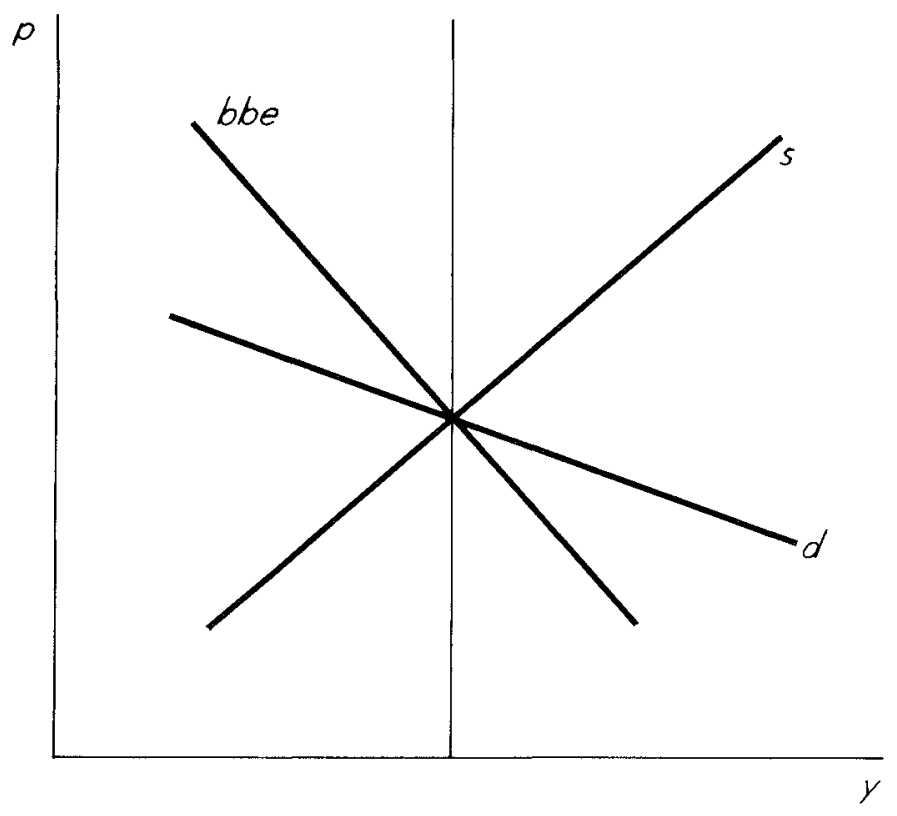

Figure 3.1 
consider an increase in real government expenditures (or a lower tax parameter). This raises the balanced budget line to the position $b b e_{1}$, and the pseudodemand line to $d_{1}$ (see Figure 3.2). The fiscal stimulus thus immediately raises output, price level, and interest rates. It also produces a deficit expressed by the distance of the $b b e$ line from point $A$, which describes the new flow equilibrium. Suppose for the moment that the deficit is financed with a new issue of government bonds. The resulting increase in the stock of securities and interest rates pushes the bbe line further upward along the (vertical) normal output line. The net effect of a bond-financed deficit thus depends crucially on the interaction between asset markets and output markets. This interaction determines the movement of the pseudodemand curve relative to the balanced budget line induced by the fiscal action. The result depends, within the context of the IS/LM framework, on the relative magnitude of the vertical shifts imposed on the two curves. A comparatively larger upward shift of the IS curve due to wealth effects induced by the bond issue raises the $d$-line, whereas a comparatively larger wealth effect operating on the LM curve lowers the line. The Brunner-Meltzer asset-market analysis yields a somewhat more complex pattern modifying the wealth effect with substitution effects between financial and real assets. The absorption of a larger stock of government securities by the asset markets unleashes offsetting

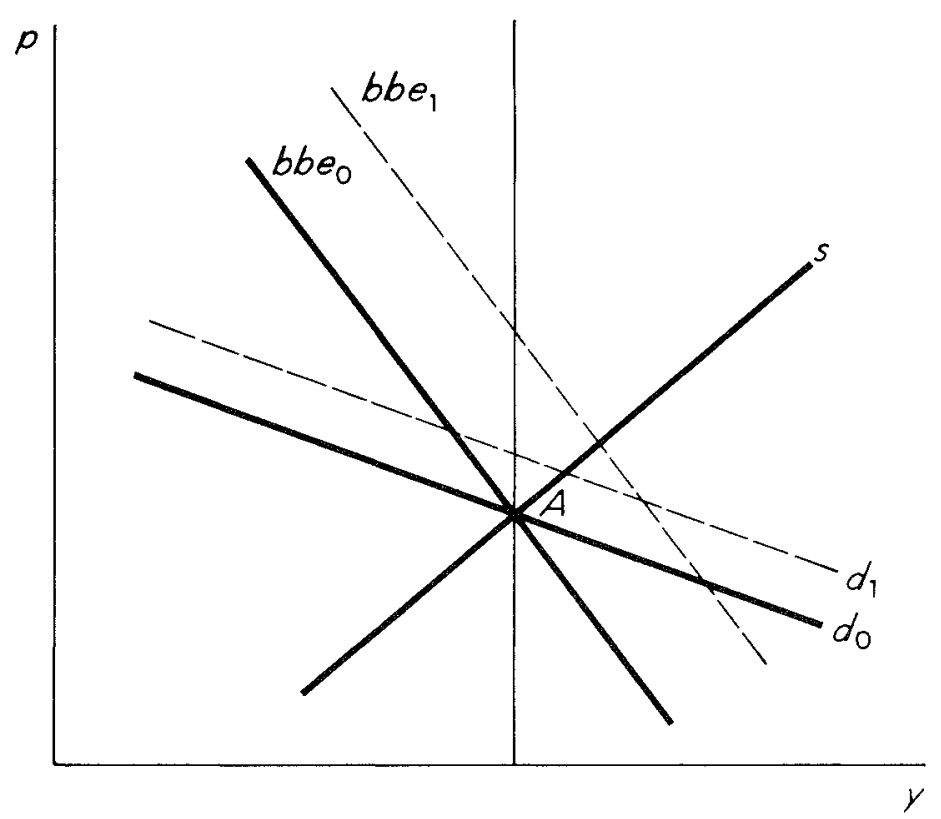

Figure 3.2 
influences via interest rates on financial assets and via the asset price of real assets. The net effect thus remains quite ambiguous without constraining order conditions. Neither argument thus yields, without specific order constraints, a definite answer. Even a positive response of the $d$-line is not sufficient, however, for the stability of the stock equilibrium. This stability requires that the upward shift in the $d$-line caused by deficit finance exceed the corresponding upward shift of the bbe-line. This conditions assures that the $d$-line eventually catches up with the bbe-line, and the flow equilibrium produces a balanced budget.

Some variations in the analysis occur at this point. Some authors emphasize the transitory nature of movements along the $s$-curve. The latter will shift upward in response to adjustments in the expected price level. The final state of equilibrium will thus tend to the normal output line. But the conditions for stability appear under either the IS/LM or the Brunner-Meltzer analysis quite unlikely. Instability associated with insufficient nonnegative or even negative responses of the $d$-line appear more likely in the context of both analytic arguments.

In contrast, consider the case of a deficit financed with new base money. The $d$-line is definitely raised, whereas the $b b e$-line is not further raised by the increase in the money stock associated with deficit finance. The stability of the stock equilibrium is thus ensured under the circumstances. The $d$-line eventually intersects the bbe-line on the vertical. Several aspects should be noted here. The total effect on the price level (and on output in case the nature-rate hypothesis is rejected) is a multiple of the "immediate" effect associated with the flow equilibrium response to a fiscal impulse. The latter is described by the shift of the state point to point $A$, whereas the final state of stock equilibrium is controlled by the intersection of the budget line and the normal output line. The total effect of a bond-financed deficit is even large in case the stability conditions is imposed. This follows from the fact that the $b b e$-line moves during the adjust process beyond the position determined by the initial rise in real government expenditures. The total effect thus reflects in both cases the financial repercussions of fiscal policy decisions.

The implications of the more likely unstable bond-financed deficit process deserve some more attention. Carl Christ (1979) emphasized that this result poses a problem for the imposition of a monetary rule. Such a rule confines the proportion of the deficit financed with base money below the critical level, assuring stability of the stock adjustment process whenever the deficit is sufficiently large. Brunner (1976) and, recently, McCallum (1981) emphasized the (partial) alleviation of the problem produced by economic growth. Such growth moves the flow equilibrium with the normal output line to the right and closes the gap between the state point fixed by the flow equilibrium and a given budget line. For any given nor- 
mal growth rate there exists an upper limit on the growth of real debt (and thus of the deficit) beyond which economic growth cannot produce stability; that is, the movement of the bbe-line to the right exceeds the growth-determined shift to the flow equilibrium. We should also consider that the analysis implies a negative effect of bond-financed deficits on the rate of normal growth via the longer-run adjustments in the stock of real capital.

But deficits beyond the critical level appear substantially more likely today than ten years ago. A low-level monetary growth would thus induce with substantial probability the unstable process discussed above. This process would raise real and nominal interest rates over time and lower the normal rate of real growth. None of these consequences induces within the economic system, according to either type of analysis, any feedbacks eventually terminating the process. However, we need to broaden our vision at this state and admit the interaction with the political process. The persistent increase in the real debt raises real interest rates and the relative burden of interest payments expressed by the ratio of interest payments to national income. This trend eventually induces rejection of low-level monetary growth in order to moderate the growth in real debt or even lower this stock with the aid of a higher price level. A change in fiscal regime offers an alternative avenue. The crucial conclusion from this stability analysis suggests that a stable noninflationary monetary regime is unlikely to persist in the absence of a fiscal regime effectively containing the average deficit. Both monetarist and Keynesian analysis developed at the time implied that the fiscal regime determines the longer-run opportunities of monetary policy. Alternatively, proposals for a monetary rule require supplementary proposal for a fiscal rule.

\section{The "NeoClassical" Contribution}

The last phases of the discussion summarized in the previous section overlapped with a new thrust in fiscal policy analysis. The "rational expectations revolution" also influenced, beyond the approach to monetary analysis, the analysis of the government's fiscal policy. A series of articles by Robert Barro, beginning in 1978, introduced a "neoclassical vision" into our discussion. The emerging analysis radically changed the economic significance of deficits. Deficits were interpreted similar to the deviations between current income and current consumption of private households in the context of an intertemporal allocation. The public debt and its behavior thus reflects the public sector's intertemporal optimization conditioned by the pattern of permanent and transitory government 
expenditures. But decisions to issue bonds in order to finance expenditures affect, in contrast to both Keynesian and monetarist analyses, neither real interest reates nor the price level nor, even temporarily, output and employment. The stability issue discussed above does not exist under the circumstances. Traditional notions of stabilization thus offer no relevant motivation for public debt policy. This position bearing on deficits and debt does not extend to government expenditures on goods and services and "non-lump-sum" taxation. Budgetary policies expressed by expenditure and tax decisions do exert temporary and permanent real effects. This analysis, most especially developed by Barro (1981a), actually involved aspects of government budgetary operations, which, even if known in a general sense, were long neglected by macroanalysis. Standard macrotheory typically presented the public sector as a sinkhole for goods and services produced by the private sector. Martin Bailey moved beyond this "sinkhole theory" of the government sector and considered the government's supply of goods and services to the private sector. The substitutive or complementary nature of this supply with respect to private consumption and investment may substantially modify the traditional results. Barro (1981b, 1984a) revived Bailey's neglected initiative and also elaborated more carefully the impact of non-lump-sum taxation. He also revived in this context some earlier work by Miller and Upton (1974). The analysis addressed, beyond these aspects, different mechanisms yielding the real effects of budgetary decisions. It shares with monetary analysis an emphasis on wealth and substitution effects, in contrast to the Keynesian reliance on the income multiplier. Its emphasis on perpetual market clearing relative to all ongoing shocks differentiates it from both Keynesian and monetarist arguments.

\subsection{The "Ricardian Theme"}

Barro must be credited for having revived a theme originally considered by Ricardo. The stability analysis examined above assumed that the financial decision between bonds and taxes exert a permanent real effect. Barro's argument persuasively challenges this position. He emphasizes that the traditional argument neglects to incorporate the future tax liability associated with current borrowing. A careful separation of issues requires, in this context, the assumption of lump-sum taxes. This assumption permits us to isolate the possible effects attributable to financial decision as such without contamination with the real effects of distortionary taxes. The forward-looking behavior emphasized by rational expectations interprets deficit finance essentially as an intertemporal reallocation of taxes. This implies that current deficits, expressed by a new sale of bonds, correspond to a shift of taxes from the present to the future. The present 
value of the forfeited (current) tax thus equals the present value of the future tax liability. This equality holds under an important assumption introduced by Barro and discussed subsequently. It holds, in particular, whether the bonds issues are maturing at a specified recognized date, according to a contingent state pattern (Chan 1983), according to a probability pattern over time, or, lastly, whether the bonds are perpetuities.

The "Ricardian argument" requires the formal apparatus of intertemporal budget constraints for both a representative household and government. A first simple argument confines the repayment period of debt to the representative taxpayers economic horizon. This constraint can be used to demonstrate that the present value of the future (expected) government expenditures plus the inherited government debt are equal to the present value of expected future taxes. Similarly, the household's budget constraint shows that the sum of present value of expected future consumption and the present value of expected future taxes is equal to the present value of expected future income plus inherited assets. Any temporal reallocation of taxes combined with an unchanged stream of government expenditures produces an equality between current non-taxfinanced government expenditures and the present value of future changes in tax liabilities. This result follows from the government's budget constraint. It implies in conjunction with the budget constraint of the representative household that the household's real opportunities are invariant with respect to the deficit. The household's wealth position defined by its present value of consumption remains unaffected and so does the present value of taxes and income. Households find the optimal choice of consumption pattern unchanged under the circumstances. The creation of a deficit thus cannot modify household consumption decisions. Substitution effects induced by distorting incentives are, moreover, excluded by the lump-sum character of taxes. The household's prior optimal consumption plan extends to the new situation, whatever the representative household's utility function may be. The deficit thus induces neither an intertemporal substitution nor a scale effect on consumption. The current deficit is perfectly matched under the circumstances by an increase in household saving. The government sector's dissaving is thus fully offset by additional private saving. The economy's total saving is therefore independent of the government's financial decision. This saving provides the necessary funds to absorb the new bonds into the household's portfolio. Optimal portfolio management determines this link between deficits, household saving, and bond acquisitions as a consequence of rational hedging. With portfolios optimally adjusted in terms of risk-return combinations before the new deficit emerges, households will find it advisable to hedge the expected tax liability by acquiring a corresponding amount of bonds. The optimal portfolio position will 
thus be maintained. In terms of the Brunner-Meltzer asset-market model, this result implies that the public's net (stock) supply of government securities disappears in the credit-market equation. It follows that variations in the stock of government securities exert no effects on asset markets. Asset prices and interest rates will not be affected. It follows, moreover, with respect to the stability analysis of Section 2 that the $d$-line remains unaffected by the government's debt finance.

The argument establishing the Ricardian thesis is crucially conditioned by the two budget constraints. These constraints involve several important assumptions that decisively determine the conclusions. Barro explored these assumptions in careful detail and argued persuasively their a priori reasonableness as a good approximation to reality. Buiter and Tobin (1978) and Tobin (1980) examined the underlying assumption with a matching vigor and argued persuasively their a priori unreasonableness as an approach to reality. There is no need to reproduce these excellent discussions here in depth. My comments concentrate on three aspects associated with the intertemporal budget constraints. These aspects bear on the horizon of the representative household, the nature of capital markets, and risks or uncertainties associated with deficit finance.

The simple fact of mortality combined with our knowledge of demographic structure and debt policies destroys the assumption that the representative household's horizon is at least as long as the repayment period of debt associated with a given tax cut. An "infinitely" living household would circumvent this problem for the Ricardian theme. Barro provided a subtle and extensive analysis interpreting this assumption in empirical terms. He introduced the notion of "operative intergenerational bequests and transfers" to link finitely living generations within an infinitely operating household. This is achieved analytically with an ingenious device. The utility of each generation depends on the utility level of the next generation. The implicit nesting of utility functions yields the appearance of an infinitely living decision unit. This does not imply that the consumption of future generations is equally weighted as the present generation's own consumption. Its implication denies, however, the dependence of consumption pattern on age characteristics of life cycle theories. Optimal consumption choices of infinitely living households produce a preferred pattern of intergenerational transfers (in either direction). Any intrusion by the government to modify this pattern via its budgetary operations necessarily fails under the circumstances. Impositions of tax burdens on future generations via a bond-financed deficit induces offsetting transfer of wealth from the present to the future generation financed with the additional current saving produced by the tax cut. The voluntarily determined optimal pattern of intergenerational transfers dominates the outcome and overrides or offsets the government's 
budgetary operations. The extension to an infinite budget constraint still assures that any cut in current taxes is exactly balanced by the present value of future tax liabilities. A shifting of the tax incidence beyond a mortal man's life span does not change his optimal intertemporal choice. The initial choice prevailing before the intertemporal tax shift remains optimal. This result implies that current tax cuts yield no wealth effects on current consumption or other real variables.

\subsection{The Ricardian Theme: Its qualification}

3.2.a. Intergenerational altruism and intergenerational selfishness. The invariance of intergenerational transfers with respect to budgetary operations is crucially conditioned by the assumption of "intergenerational altruism." This assumption justifies the infinite horizon. Consider, in contrast, the opposite assumption, "intergenerational selfishness," combined with the life cycle hypothesis of consumption (Kotlikoff 1984). The latter hypothesis implies that the marginal propensity to consume increases with age. The assumption of "intergenerational selfishness" reenforces this pattern as older generations plan no bequests under the circumstances. Any transfer between generations modifies in this case aggregate real consumption. In particular, a transfer from the younger to the older generation raises aggregate consumption. A shift in taxes from the old to the young would produce this result. Replacing some current taxes with bonds maturing during the young generation's lifetime after the older generation's death would accomplish the necessary shift. The result emerges with even larger weight whenever the future tax liabilities fall on unborn generations. "Intergenerational selfishness" thus assures that any temporal reallocation associated with a deficit induces intergenerational transfer not "washed out" within an infinite intertemporal budget constraint. The intergenerational transfers are not offset and produce real consequences. They actually modify the relevant budget constraint for each generation.

The difference between the two cases may be conveyed in the following terms. Let the expression

$$
A_{i+1}+C_{i}+T_{i}=Y_{i}+A_{i}
$$

denote the $i$ th generation's budget constraint, where $A_{i+1}$ indicates the bequests transmitted to generation $i+1$ by generation $i . C_{i}, T_{i}$, and $Y_{i}$ describe the present value (as of generation 0 ) of consumption, taxes, and income for generations $i$ over its lifetime. With intergenerational altruism $A_{1}$ reflects the optimal transfer decisions in response to changes in $T_{0}$ and the matching changes in $T_{\mathrm{I}}$. Thus follows the relevance of the infinite 
budget constraint. Intergenerational selfishness breaks up this pattern. Its strict and narrow application means that $A_{i+1}=0$. A change in $T_{0}$ thus invariably induces a change in $C_{0}$ that exceeds, with the differential in marginal propensities, the change in $C_{1}$ in the initial period.

This analysis suffers, however, in comparison with the "intergenerational altruism" model from some immediate confrontation with reality. We do observe that wealth is actually transmitted from one generation to another. These transfers are excluded by the narrowly formulated "selfishness model." The occurrence of transfers is, however, not necessarily an expression of voluntary and planned transfers associated with intergenerational altruism once we move beyond the context of perfect information. Blanchard (1984) argued that an insurance scheme under risk yields the same result of no bequests. But such insurance does either not exist (specifically the one used by Blanchard) or it at most only used or offered partially by agents. But bequests apparently do occur. The context of risk could explain, however, the appearance of bequest without the bequest motive as formalized by Barro. Agents face some probability that the remaining life span exceeds the expected time. Risk averse agents will therefore adjust the use of their wealth in view of this uncertainty. Their problem is similar to the asymmetric risks associated occasionally with inventory decision. The asymmetry is probably even more acute in this case. Using up all resources before death exposes a person to serious hazards. This is balanced by unused resources at death, reflecting lowered consumption before death. The comparatively lower level of consumption can be understood as a premium paid for selfinsurance against the hazards of early exhaustion of one's resources. Wealth will be held under the circumstances beyond the requirements of the statistical expectations bearing on the remaining life span. It follows that, on average, unused wealth will be transmitted at death to the next generation without an "operative bequest motive." Intergenerational transfers operated by budget deficits would in this case still raise current consumption. The observation of substantial intergenerational transmission of wealth is thus consistent with the denial of "Ricardian equivalence."

It should be noted that this argument disregards the potential role of annuities to be purchased by the older generation. But even an actuarially fair supply of annuities would probably not completely replace the holding of tradeable wealth as insurance for old age hazards expressed by only partially insurable large expenses on health problems. The annuity business, moreover, operates at a cost. A comparison of this cost with the cost of self-insurance could be expected to have a margin of tradeable wealth. But an entirely different argument, developed by Bernheim, Shleifer, and Summers (1985), explicity recognizes the occurrence of 
voluntary planned bequests and offers probably a more relevant critique of the Ricardian thesis of debt neutrality. This analysis will be examined in subsequent sections covering the empirical work.

3.2.b. Corner solutions. The alternative hypotheses yield very different interpretations of social security. The Ricardian theme implies that such arrangements are offset by correspondingly larger transfers from the older to the next generation with no effect on current consumption. The alternative, articulated by Feldstein (1982), implies that this intergenerational transfer raises current consumption. An interesting explanation of the emergence of social security (Meltzer and Richard 1985) reenforces the "non-Ricardian" hypothesis. Social security is interpreted as a substitute for the voluntary social arrangements made within the larger family. Social evolution gradually eroded such arrangements and raised the older generation's control problem associated with the extraction of the support. Social security emerged as a political solution to this problem. This explanation cannot be reconciled with a Ricardian equivalence. Its basic structure asserts, on the contrary, that the intergenerational link described by Barro has been suspended. This interpretation suggests, moreover, the occurrence of several important facts bearing on intergenerational transfers. Such transfers do not occur solely in the form of a tradeable wealth accumulated by the older generation and eventually inherited by the younger generation. Voluntary intergenerational transfers may frequently involve an intertemporal exchange between older and younger generations. The older generation invests initially in health, education, and other dimensions of the younger generation with the expectation of support (i.e., negative bequests) during old age. The extraction of support does not proceed without control and transactions costs, however. The hypothesis indicated above states basically that specifiable social changes raised these costs and increased the likelihood of corner solutions when unrestricted optimality yields negative bequests. Under the circumstances the government's intervention increases current real consumption. Lastly, we note that this argument also suggests that a single representative household does not adequately represent the actual diversity encountered in matters of intergenerational transfers.

The representative household's infinite intertemporal budget constraint requires, in addition to the special intergenerational link, an assumption about capital markets. This assumption removes the occurrence of another solution. The representative household's lending and borrowing rates coincide with the rates available to the government's operation. A violation of this conditions produces wealth effects that suspend the Ricardian equivalence. Chan (1983) explored this theme in the context of an assumption approximating the problem in terms of liquidity constraints imposed on a subset of households. A debt-financed deficit operates 
under the circumstances to substitute government borrowing for constrained household borrowing. Households with no liquidity constraint or a nonbinding one respond to the deficit and its finance in the "Ricardian manner" with the offsetting behavior discussed above. Households suffering binding liquidity constraints before the event experience, through the intermediation of the government, a relaxation of the constraint. They will react by shifting future consumption into current consumption. The distribution of significant liquidity constraints or the distribution of differential borrowing rates of interest between government and households determines the net effect of a debt-financed tax cut on households' current consumption.

Some fundamental theoretical exploration about the conditions for Barro's "operative intergenerational bequests" qualifies the debt neutrality result. Barro's analysis is conditioned by the assumption that intergenerational transfers from old to young occur independently of debt. The emergence of debt changes neither opportunities nor preferences in the world described. No real consequences thus ensue. An interior solution is simply maintained. Philippe Weil (1984) examined the problem with great analytic care. His basic theme emphasizes the existence of a "deep connection between the efficiency properties of overlapping generation economies without bequest motive and the possible direction of intergenerational transfers." There exist, in particular, overlapping generation economies that "justify," in terms of efficiency, intergenerational transfers from young to old. Weil demonstrates that the existence of "operative bequests" in a suitably defined steady state depends on the discount applies by the old to the future utility of the young. This discount should not exceed a benchmark determined by the gap between the interest rate and economic growth in a diamond-type model. Weil concludes that a "wide class of economies with a bequest motive" do not satisfy Barro's proposition about Ricardian debt neutrality. The limited significance of this analysis should be clearly understood. It essentially establishes that Barro's result is nonvacuous and places necessary and sufficient conditions on its occurrence. This purely analytic result cannot settle the crucial empirical issue at stake.

3.2.c. Risk and uncertainty. Risk and uncertainty are essentially exorcised from the argument supporting the Ricardian theme. A firm link connects the household's benefits from the current tax cut with the future tax burden. The government's infinite intertemporal budget constraint also removes all risk and uncertainty with regard to the government's budgetary operation. Agents can rest assured that future tax liabilities guarantee the crucial equality of present values.

The pattern is substantially modified once we admit risk and uncertainty on two levels into the analysis. Barro (1981a) and Feldstein (1982) 
already noted in passing some consequences associated with uncertainty about the households' future tax liability. Barro suggested that uncertainty raises the perception of the present value attached to future tax liabilities by risk-averse households. Thus a debt-financed deficit lowers under uncertain future tax liabilities the representative household's perception of its wealth position. Current private consumption thus declines as a result of the deficit. The suggestive remark was developed by Chan (1983) in some explicit analytic detail. The argument still adheres to a state of lump-sum taxes with certainty concerning the future aggregate tax liability. Households suffer, however, incomplete information and consequently experience some risk about the distribution of the global burden among the taxpayers. The individual household's future tax burden is determined by a stochastic process. It follows that the individual's share of the current tax cut does not match his share of the future tax liability. This suspension of the crucial link produced by a stochastic tax incidence implies, under conventional restrictions on preferences, that a debtfinanced deficit lowers current consumption. The larger the uncertainty about the incidence of the future tax liabilities, moreover, the larger is the negative effect of a deficit on current consumption. The result reveals that households hedge against the risk imposed on them by saving even more than determined under certainty. The hedging response induces a substitution of saving at the expense of consumption.

A similar theme, but different in its conclusion, was recently developed by Barsky, Mankiw, and Zeldes (1984). Risk-averse households encounter in this case not an uncertain tax incidence but an uncertain future income. An intertemporal reallocation of tax liabilities (with less now and more in the future) lowers the degree of uncertainty bearing on future income. The precautionary demand for savings declines and real consumption increases under the circumstances. This result is, moreover, produced under strict "Ricardian conditions."

The analysis proceeds in the context of a two-period model characterized by three budget constraints. The two constraints describing the household's position appear as

$$
\begin{gathered}
W_{1}=\mu_{1}-C_{1}, \\
C_{2}=(1+R) W_{1}+\mu_{2}+\epsilon_{2},
\end{gathered}
$$

where $C_{1}$ and $C_{2}$ refer to consumption in periods 1 and $2, \mu_{1}$ and $\mu_{2}+\epsilon_{2}$ designate income in the two periods, $W_{1}$ defines savings in period 1 , and $R$ is the interest rate. The magnitudes $\mu_{1}$ and $\mu_{2}$ are nonstochastic, whereas $\epsilon$ is the stochastic component of future income. A temporal tax shift is introduced by inserting $T$ positively in Eq. (2) and $(1+R) T$ nega- 
tively in Eq. (3) The signs are determined by the fact that any initial tax burden is impounded into $\mu_{2}$ and $\mu_{2}$. We thus rewrite the household's budget constraints as

$$
\begin{gathered}
W_{1}=\mu_{1}+T-C_{1}, \\
C_{2}=(1+R) W_{1}-(1+R) T+\mu_{2}+\epsilon .
\end{gathered}
$$

The government needs to levy taxes in the second period in order to finance the repayment of $(1+R) T$. The required tax rate is thus determined by the relation

$$
(1+R) T=t \mu_{2} .
$$

The revenues from extra taxation imposed on expected income should cover the repayment. The actual tax revenue is

$$
t\left(\mu_{2}+\epsilon_{2}\right)=(1+R) T+\frac{(1+R) T}{\mu_{2}} \epsilon_{2} .
$$

The second period's household constraint can thus be rewritten once more as

$$
C_{2}=(1+R) W-(1+R) T+\mu_{2}+\left[1-\frac{(1+R) T}{\mu_{2}}\right] \epsilon .
$$

Lastly, the authors postulate a three-times differentiable utility function in $C_{1}$ and $C_{2}$ satisfying the conditions

$$
(1+R) U_{222}-U_{122}>0 .
$$

The first-order optimality conditions are immediately derived:

$$
E U_{1}\left(C_{1}, C_{2}\right)=(1+R) E U_{2}\left(C_{1}, C_{2}\right) .
$$

A straightforward manipulation of this condition yields the marginal propensity to consume:

$$
\frac{\partial C_{1}}{\partial T}=\frac{(1+R) \operatorname{Cov}\left[(1+R) U_{22}-U_{12}, \epsilon\right]}{-\mu_{2}\left[E U_{11}-\partial(1+R) E U_{12}+(1+R)^{2} E U_{22}\right]}>0 .
$$

A reduction in current taxes, appearing as a position magnitude in the constraint, thus raises current consumption. Tax policies induce, under the circumstances, specified real effects in the economy. These effects emerge even with the households' definite perception that the present value of its expected future tax liabilities equals the taxes foregone in the 
present. The result is crucially conditioned by the positive covariance term in Eq. (8). This result vanishes in the absence of the third-order derivative condition imposed on the utility function. Once we accept this condition the crucial aspect centers on the reduction in the variance of second-period income produced by a nonvanishing tax rate $t=(1+R) T / \mu_{2}$. The variance is actually reduced in the proportion $(1-t)^{2}$

The authors offer two distinct interpretations for the two-period model. One confines the model to the lifetime of a single individual. Income uncertainty bears in this case on an individual's uncertainty within the life cycle. The other interpretations introduce intergenerational relations. The second period refers to the economic uncertainty attached to a household's descendants. The uncertainty of both cases is incisively demonstrated by the authors. Extensive simulations proceeding under a variety of assumptions offer some insights beyond the qualitative result in Eq. (8) about the order of magnitude of tax effects on real consumption.

The issue addressed by Barsky, Mankiw, and Zeldes was already analyzed by Chan (1983). The detailed formulation differs slightly, but the conclusion is the same once the preference structure is properly restricted. Chan emphasizes, however, that the insurance scheme introduced with the special tax policy arrangement is essentially independent of the debt-tax mix problem.

The infinite intertemporal budget constraint of government also reflects a crucial link suspending relevant risks and uncertainty. The equality of present values of expenditures and taxes expresses agents' certain knowledge that current expenditures will eventually be covered by taxation. Suppose, however, that large debt-financed deficits persist for 10 , 100 , or 1000 years. Is it reasonable to assume an invariant certainty that after $x+1$ years all will be unwound with appropriately increasing tax liabilities? The basic thrust of rational expectations would suggest that agents learn. An experience of accumulating debt-financed deficits would induce doubts and reservations about the relevance of infinite intertemporal budget constraints. The time-inconsistency problem diligently discussed with examples from tax and monetary policies should actually be highly significant in this context (Baltensperger 1984). Suppose that agents were exposed to a long series of deficits financed by issues of interest-bearing debt. This experience induces some revisions in agents' expectations. The probability assigned to possible defaults, particularly to default by inflation, will rise under the circumstances. The increasing risk associated with large and persistent deficits generates over time an anticipated purchasing-power risk attached to the government debt. This purchasing-power risk modifies the Fisher equation with the appearance of a specific covariance expression representing the purchasing-power risk. 
The emergence of this risk term implies an increase both of the nominal and the real rates of interest (Baghat and Wakeman 1983). This problem will be reconsidered in a subsequent section attending to the long-run interdependence of monetary and fiscal policies, an issue raised by Sargent and Wallace (1982).

3.2.d. The changing nature of the issue. The risk problem introduced in the previous paragraph bears essentially on long-run aspects associated with the cumulative effects of a long series of large deficits that erode the relevance of the infinite intertemporal budget constraint expressed in terms of ordinary taxes. This seems to be not the only aspect of risk and uncertainty associated with the macroeconomic consequences of the government's budgetary process. Such risk and uncertainty have so far not been integrated into macroeconomic analysis. Our most recent fiscal experiences suggest that a potentially useful research program would examine the impact of the uncertain amount and nature of tax liabilities on the public's balance-sheet risks and consequently on asset markets, with further effects on consumption and investment. This investigation moves us substantially away from the "Ricardian theme." This theme, restrained by the assumption of lump-sum taxes in order to isolate a possibly pure public-debt effect, can only admit uncertainty about the temporal distribution, the personal incidence of tax liabilities and future income. The first type of uncertainty does not modify the Ricardian theme, but the second and third violate the neutrality pattern of debtfinanced deficits. Risk and uncertainty surrounding tax liabilities have a much wider field of operation once we introduce "non-lump-sum" taxes. The uncertain incidence of future tax liabilities on nonhuman wealth, human wealth, and consumption probably affects portfolio risks and thus the required average return. The consequent adjustment in asset values modifies consumption, saving and investment patterns. The importance of debt-financed deficits may, in this context, not so much emerge because of a direct effect of public debt on real interest rates in defiance of any "Ricardian equivalence." The deficits and the resulting increase in public debt yield possibly their most important effects via a different channel. These phenomena may be a signal of mounting uncertainty about future magnitude and incidence of tax liabilities. Agents' perceptions bearing on the interpretation of observed deficits would operate as a crucial link in the process. Balance-sheet risks and asset-market responses will vary with the perceived duration of the deficit.

This theme also offers an avenue for an analysis of fiscal regimes in contrast to the usual analysis of fiscal policy actions and their effects on the evolution of economic activity. Fiscal regimes could be differentiated according to their respective risk patterns parameterized in a specific mode. The procedure would follow the imaginative attempt made by 
Stulz and Wasserfallen (1985) for the case of monetary regimes. The investigation was motivated by the recognition of the comparative importance of the stochastic trend and the relatively modest significance of the stationary component in economic fluctuations (Nelson and Plosser 1982). The array of specific policy actions addressed to the cyclic component remains, under the circumstances, confined to a smallish range of influence. Stulz and Wasserfallen show that, in contrast to influences exerted by specific actions, the influence of the regime's characteristics expressed by some risk parameters substantially contribute to global economic evolution by conditioning the properties of the stochastic trend. The uncertainty imposed by the regime affects the stochastic properties of assets, their risks, and the portfolio risk with consequences on returns and output behavior. These issues seem worthy of further exploration in a program designed to integrate finance and macroeconomic analysis (Lucas 1984; Plosser 1984; Fischer and Merton 1984).

3.2.e. Some final remarks on the Ricardian theme. It is interesting to reflect at this stage on the consequences of the discussion initiated with Barro's revival of the Ricardian theme. The neoclassic analysis rejects the "conventional" position that the government's financial decisions expressed by the debt-tax mix induce real consequences over both the short and long runs. The IS/LM framework concentrated on the wealth effects of debt policies as the crucial condition of real effects. The Brunner-Meltzer asset-market analysis, on the other hand, emphasized the comparative small order of wealth effects associated with a pure-debt policy even when future tax liabilities were disregarded. The wealth effect measured as the vertical shift elasticity of the pseudodemand line in figure 3.1 occurs as a product of two terms. One term consists of components with opposite signs reflecting offsetting influences produced by interacting asset-markets. The other term is the ratio of government debt at market value to total nonhuman wealth. The real consequences of debt policies in the Brunner-Meltzer asset-market analysis were dominantly produced by substitution and relative price effects produced by the shifting composition of assets. The discussion of the stability analysis revealed furthermore that this short-run, pure-debt effect, again evaluated by shifts of the pseudodemand line, is at best very modest with respect to aggregate output and the price level. This portion of "conventional" analysis assigned more significance to the long-run effects of a pure-debt policy centered on the adjustment of the optimal stock of real capital and consequently the position of the normal output line in Figure 3.1. Both mechanisms stressed by conventional analysis became suspended in the neoclassic analysis. Intergenerational altruism and optimal hedging removed both wealth and substitution effects.

The discussion seems hardly to restore the "conventional" position. Its most significant elements modifying the Ricardian theme do not suggest 
much potent effects of debt-tax mix policies per se. Kotlikoff's analysis directs our attention neither to any wealth nor subsitution effects. This analysis implies, based on the assumption of "intergenerational selfishness," that debt policies induce intergenerational wealth transfer that modify current real assumption. Debt policy is, however, not a necessary condition of such transfers. Such transfers may occur without debt policy as a result of nontemporal tax shifts. But debt policies do induce, on the other hand, the transfers described by Kotlikoff. This analysis thus emphasizes the effect of debt policies on the composition of aggregate real demand. Debt policies raise real consumption and lower real investment in the short run and lower (comparatively) the capital stock and normal output in the long run. But the mechanism involved differs from those described by conventional analysis. We note, however, that Kotlikoff's analysis is consistent with the operation of a wealth and substitution effect (via asset markets) induced by debt policy.

The consequences of risk and uncertainty induced by debt-financed deficits, so clearly visible in the past five years, may also trace potentially important transmission channels for debt policies. The papers by Baltensperger and Chan are somewhat suggestive in this respect. The issue raised by Baltensperger suggests that an increasing risk of default by inflation associated with a permanent, large, debt-financed deficit raises the purchasing-power risk of government debt and consequently raises the (gross) real rate of interest. An alternative mode of approaching the same issue proceeds along lines suggested by Bomhoff (1983), Mascaro and Meltzer (1983), and Evans (1984). Permanent and large debt-financed deficits contribute to uncertainty about the course of monetary policy. This uncertainty produces a risk premium embedded in interest rates and raises real rates. And once we move beyond the realm of pure-debt policies and consider deficit policies in a world of distortionary taxes, the risk problem appears, on a first impression, to magnify. But we still lack at this stage an adequate analysis of portfolio risks induced by persistent deficits and the associated uncertain course of tax policies. This analysis would also extend to the effects of such portfolio risks on real consumption, investment, and real returns of assets. We may ultimately learn from the work initiated by the "Ricardian discussion" that the "Ricardian world" offers similar to the Modigliani-Miller theorem a useful benchmark for any analysis of our real problems. It may well be that the new analysis gradually emerging yields insights into more significant mechanisms associated with debt-financed deficits than elaborated by "conventional analysis."

\subsection{Some recent empirical work on the Ricardian theme}

Analytic arguments and counterarguments hardly settle the issue. They may establish some presumptions with varying weights. An uncertain 
incidence of future tax liabilities seems to be, for instance, a better approximation to reality than the matching of the distributions of current tax cuts and future tax liabilities. The fact of uncertainty appears clearly more acceptable than its denial or the postulated perfect matching. The approximate realization of such matching in the tax cuts effected on the basis of the Kennedy or Reagan decisions would be, in my judgment, quite astonishing. The matching would have to be reflected in a corresponding matching of experienced tax reductions, additional savings, and resulting acquisitions of government bonds. Simple institutional facts (size of denomination relative to tax cut, access costs to capital markets) distort the pattern and most likely prevent an approximate matching between tax cuts and bond acquisitions, even with a maintained matching between tax cuts and savings. But the partial distortion of the matching need not be decisive per se. The nonmatching segment of taxpayers may be concentrated toward the lower end of the income distribution involving a smallish fraction of total tax cuts. Alternatively, these taxpayers may invest the accrued savings in one form or another of indirect claims on bonds. The financial intermediation involved in this case usually redistributes risk between the intermediary and the holder of its liabilities. The more or less indirect claims on bonds are thus not equivalent to bonds. A positive but smallish wealth effect could thus emerge. But an empirical assessment of the Ricardian thesis along these lines seems very costly and quite uncertain.

A study of another major implication bearing on bequest patterns may be more promising. The Ricardian theme implies that any tax cut relative to permanent government expenditures induces adjustments of bequest by the older generations in order to maintain the utility level of the subsequent generation. A similar effect occurs with changes in social security benefits (i.e., negative taxes) for the older generation. The studies actually executed so far (Feldstein 1978; Barro 1978) yielded conflicting results. A direct examination of bequest patterns linked to major tax-policy shifts could add some information. The Ricardian theme implies, however, in the context of our actual age distribution and conditional life expectation a somewhat loose relation between relative tax cuts and additional bequest. Some of the anticipated tax liabilities will still be borne by the "older" agents. A tighter relation should prevail between relative tax cuts and additional savings, however.

Assessments based on some of the crucial linkages emphasized by the Ricardian hypothesis require a large amount of rather specific information in order to produce approximately useful results. The operation of liquidity constraints offers a good example. There is good evidence for the relevant occurrence of such constraints for some segment under the wealth distribution. We know from various studies that there exist social 
groups which confront borrowing rates massively higher than the government's borrowing rates. But it is difficult and somewhat speculative to assess the relative significance of this fact without detailed additional cross-sectional data. Professional research quite sensibly attemped, under the circumstances, another route. Early investigations by Tanner (1970) and Kochin (1974) explored the implication bearing on the invariance of consumption expenditures with respect to government debt or debtfinanced deficits. Buiter and Tobin (1978), among others, followed these efforts. The net result of this early round was hardly conclusive, with some diversity of results. Six more recent studies by Feldstein (1982), Kormendi (1983), Aschauer (1985), Plosser (1982), Boskin and Kotlikoff (1985) and Bernheim, Shleifer, and Summers (1985) are selected for closer examination.

3.3.a. Feldstein. Feldstein expresses the major implication of the Ricardian thesis in terms of specific constraints on the coefficients in a regression. This regression relates consumers' expenditures $(C)$

$$
\begin{gathered}
C=\beta_{0}+\beta_{1} Y+\beta_{2} W+\beta_{3} S S W+\beta_{4} G+\beta_{5} T \\
+\beta_{6} T R+\beta_{7} D+\mu
\end{gathered}
$$

with the relevant variables under consideration, where $Y$ is national income, $W$ wealth, $S S W$ measures social security wealth, $G$ expresses government expenditures, $T$ taxes, $T R$ transfer payments, $D$ total government debt, and $\mu$ is a random term. All variables are measured in real terms per capita. The Ricardian hypothesis implies the following patterns:

$$
\beta_{5}=0, \quad \beta_{6}=0, \quad \beta_{3}=0 \text { and } \beta_{7}=-\beta_{2} .
$$

The last condition assures that an increase in measured wealth due to government debt exerts no effect on real consumption. Feldstein considers, in addition, a special "fiscal impotence" hypothesis defined by the four conditions listed plus $\beta_{4}=-1$. This hypothesis does not, however, represent the neoclassical position developed specifically by Barro. This problem will be discussed in a subsequent section. The rejection of $\beta_{4}=-1$ yields, in particular, no evidence bearing on the Ricardian thesis.

Feldstein concludes an examination of 11 distinct estimations of the regression equation with the judgment that government spending and taxes "can have substantial effects on aggregate demand." He also concludes that "each of the implications of the pre-Ricardian equivalence hypothesis is contradicted by the data." This strong and unambiguous conclusion is somewhat puzzling when evaluated against the results 
obtained from the regression analysis. The reader may judge for himself with the aid of the following table. This table compares the frequency among the regression results with which the standard error of the coefficient estimate se exceeds or equals the coefficient estimate of $c e$, and the number of cases with a coefficient estimate at least double the coresponding standard error.

\begin{tabular}{ccc} 
& se $>c e$ & $c e>2 s e$ \\
\hline$\beta_{5}$ & 7 & 2 \\
$\beta_{6}$ & & 7 \\
$\beta_{3}$ & 10 &
\end{tabular}

The last condition-that is, $\beta_{7}=-\beta_{2}-$ can only be judged on the basis of three regressions. Two cases confirm the hypothesis, and one case provides negative evidence. This pattern is really rather mixed and hardly offers a decisive rejection of the Ricardian thesis. The condition on transfer payments (i.e., $\beta_{6}=0$ ) emerges as the clearest, but not particularly overwhelming, rejection. The other results bearing on the remaining three conditions seem actually more supportive with respect to the Ricardian thesis.

Several issues associated with the regression analysis obscure the interpretations and assessment of the results. The taxes used naturally refer to "non-lump-sum" taxes with their specific incentives and disincentives. Even a highly significant $\beta_{5}<0$ would be difficult to interpret under the circumstances. We also note that the error-structure problem explored by Plosser and Schwert and the issues associated with potential nonstationarity are neglected.

3.3.b Kormendi. Kormendi recently offered an interesting paper exploring our subject. His discussion expands the role of government following the suggestions of Martin Bailey. The government sector is essentially recognized as a production sector supplying consumption and investment goods. It also operates with a "dissipation factor" representing the social cost of government production. A "consolidated explanation" of private-sector real consumption (excluding purchases of consumer durables) is developed according to the rationality concept of the neoclassical position. This means that households' information about their available resources or opportunities fully reflects the underlying social reality without any distortion of their perceptions. The resulting consumption function is represented by the regression

$$
P C_{t}=a_{c}+a_{11} Y_{t}+a_{12} Y_{t-1}+a_{2} G S_{t}+a_{3} W_{t}+a_{4} T R_{t}+u_{t},
$$

where $P C=$ personal consumption, $Y=$ net national product, $G S=$ government spending on goods and services, $W=$ private real wealth, 
and $T R=$ transfer payments. All variables are again in real terms. The "consolidated hypothesis" implies that $a_{11}>0<a_{3}$ and $-1<a_{2}<0$. The magnitude of the latter coefficient reveals the nature of the government sector's production process and of its output. Kormendi emphasizes, moreover, that $a_{4}>0$ can be reconciled with the consolidated hypothesis. This pattern occurs in case transfer payments involve a redistribution from social groups with lower marginal propensity to groups with higher marginal propensity to consume.

The comparative robustness of the "consolidated explanation" yields, in Kormendi's judgment, some initial indications of the neoclassical hypothesis. This robustness is evaluated in accordance with the procedure developed by Plosser and Schwert (1978). The results are quite satisfactory. The estimates derived from the application of ordinary least squares to level data, from generalized least squares, and from first differences coincide very closely.

A second step of the examination enlarges the regression. This yields a "nested specification" subsuming both the standard version and the consolidated explanation:

$$
\begin{gathered}
\Delta P C_{t}=a_{0}+a_{11} \Delta Y_{t}+a_{12} \Delta Y_{t-1}+a_{2} \Delta G S_{t} \\
+a_{3} \Delta W_{t}+a_{4} \Delta T R_{t}+a_{5} \Delta T X_{t}+a_{6} \Delta R E_{t}+a_{7} \Delta G I N T+u_{t},
\end{gathered}
$$

where $T X=$ taxes, $R E=$ retained earnings, and $G I N T=$ interest payments made by the government. The alternative hypotheses imply the following patterns with respect to the crucial four coefficients:

standard version: $\quad a_{2}=0, a_{5}<0, a_{6}<0, a_{7}>0$, consolidated version: $\quad a_{2}<0, \quad a_{5}=a_{6}=a_{7}=0$.

The results are quite unambiguous. The standard version is clearly rejected. The estimates of $a_{5}, a_{6}$, and $a_{7}$ do not differ significantly from zero at standard levels. An $F$-test applied to the last three coefficients confirms the consolidated version. It should also be noted that the estimates of $a_{11}, a_{12}, a_{2}, a_{3}$, and $a_{4}$ coincide with the estimates obtained from the examination of comparative robustness. The standard version implies, moreover, that $a_{5}=-a_{1}=\left(a_{11}+a_{12}\right)$. This condition is also rejected.

The test of the net wealth position of government debt yields, in view of the discussion of uncertain future tax liabilities, a remarkably interesting result. The full discounting of future tax liabilities associated with current debt finance implies that the coefficient for government debt $D$ in an extended regression including this variable must be zero. The standard version would assign, in contrast, a positive coefficient. Estimation based on a sample including the war years produces a highly significant negative 
value for the debt coefficient. The exclusion of the war years still yields a negative coefficient 1.6 standard errors from zero. The author's interpretation of the result is worth quoting:

The real income stream deriving from government debt involves inflation risk and some default risk to holders of the debt. The future tax stream implied by the debt, on the other hand, involves that same inflation and default risk plus considerable additional risk as to both its intertemporal and cross-sectional incidence. Thus, in rationally assessing the future tax consequences of government debt, the current certainty equivalent value of the future taxes may exceed the current certainty equivalent value of the income stream (which is simply the market value of the debt). In such a case, the net wealth of the private sector is adversely affected by government debt, implying a negative effect for $\Delta G B$, (and a positive effect for $\Delta T X$ ) on private consumption.

3.3.c. Aschauer. Aschauer's exploration also addresses, similarly to Feldstein and Kormendi, the implications of the neoclassical thesis bearing on households' consumption behavior. The present paper develops, however, a difference procedure. The author investigates the Ricardian equivalence proposition in the context of an intertemporal optimization framework. A rather standard separable utility function is maximized subject to a consolidated condition derived from combining the representative households and the government's budget constraint. The integrated constraint reflects the households' full recognition of the real conditions determined by the government's fiscal operation. The argument of the utility function refers to "effective consumption" $C^{*}=C+\Theta G$, defined as the sum of private-sector consumption plus a component of government spending $G$ that contribute to the households' consumption. The parameter $\Theta$ expresses the marginal rate of substitution between the two components in effective consumption. With a quadratic utility function, constraint maximization yields an Euler equation

$$
E C_{t}^{*}=\alpha+\beta C_{t-1}^{*} .
$$

The coefficients are determined by the parameters of the utility function and the constraint. Upon translation into a stochastic context, the Euler equation coincides with Hall's (1981) formulation. The latter argued that in the context of a life cycle model, $\beta=1$ and that consumption moves along a random walk.

Aschauer supplements the Euler equation with past values of the deficit $D$ and estimates the regression

$$
C_{t}=\alpha+\beta C_{t-1}+\gamma_{1} D_{t-1}+\gamma_{2} D_{t-2}+\gamma_{3} D_{t-3}+\gamma_{4} D_{t-4}+\mu_{t} .
$$


This extension was motivated by the author's concern to evaluate the impact of fiscal policy. The neoclassical position incorporated in the underlying optimization schemes implies that all the $\gamma$-coefficients are zero. An OLS estimation of the augmented regression yields a clear contradiction of the neoclassical thesis. The deficit variable contributes significantly to the explanation of private consumption $C$. The sign pattern is significantly different from zero. Aschauer argues that this result "may be more apparent than real due to the fact that past taxes and deficits may help to predict current government spending." This information content of past deficits combined with the substitution relation between $G$ and $C$ conditions nonzero levels for the $\gamma$-coefficients.

The author develops this idea in two steps. First he decomposes effective consumption $C^{*}$ in the (stochastic) Euler equation $E C^{*}=\alpha+\beta C_{t-1}$ and obtains

$$
C_{t}=\alpha+\beta C_{t-1}+\beta \Theta G_{t-1}-\Theta G_{t}^{0}+u_{t},
$$

where $G_{t}^{0}=E_{t-1} G_{t}$. Secondly, he introduces a forecasting equation for $G_{t}$ in order to relate $G_{t}^{0}$ with observations:

$$
G_{t}=\gamma+\epsilon(L) G_{t-1}+w(L) D_{t-1}+v_{t} .
$$

The last two expressions determine the system with the crucial properties to be estimated and evaluated. This system consists of the forecasting equation, Eq. (15), and Eq. (16):

$$
C_{t}=\delta+\beta C_{t-1}+\eta(L) G_{t-1}+\mu(L) D_{t-1}+u_{t} .
$$

The derivation of the system implies some cross relations linking $\eta$ with $\mu$ and $w$. These cross relations offer the relevant test statements:

(They) restrict the way in which past government expenditures and past government deficits may influence present consumption expenditure. In particular, if the Ricardian equivalence proposition does not hold, past values of the government deficit should have explanatory power for consumption expenditure apart from the role in forecasting government spending. Consequently, a finding that the data do not do violence (to the restrictions) yields some grounds on which to argue that to a first approximation, the joint assumption of rational expectations and Ricardian equivalence provides a plausible description.

The nature of the formulated hypothesis implies that the relation between constrained and unconstrained estimates determines the crucial test information. The log-likelihood ratio provides thus the relevant test statistic. 
It appears that the null hypothesis representing the neoclassical thesis cannot be rejected at a significance level lower than 24 percent. A test based on a forecasting equation for $G$ with longer lags yields a significance level of 10 percent and another test imposing additional constraints shows a significance level of 25 percent for the likelihood statistic.

3.3.d. Provisional comments. Kormendi and Aschauer manage to demonstrate that the neoclassical position represented by the Ricardian equivalence proposition cannot be so easily dismissed. The case for the conventional alternative, which assigns significance to financial decisions, is neither clear nor overwhelming. The evaluation centered on the patterns exhibited by consumption behavior so far remains unsettled and open. Adyocates of the "conventional hypothesis" (like the author of this paper) are forced to admit that the neoclassical position deserves serious investigation. Further examination may affect both the conventional and the neoclassical thesis. Neither position may survive unscathed. The suggestions concerning the role of uncertainty and risk joined with Kormendi's estimate of the debt parameter may give a clue for possible future work. Such work should, in particular, also attend to a serious gap in the papers discussed above. The Ricardian proposition implies a tight relation between relative tax cuts, additional savings and acquisitions of government debt by households. According to this proposition the induced additional savings do not spill over beyond bond acquisition to consumer durables. The absence of any significant effect of the relevant fiscal policy variables on real consumption expressed by nondurables, services, and use-value of durables offers only very partial evidence. The regressions explored need be complemented with a similar regression addressed to the investment in consumer durables and possibly other assets typically held by households that are not equivalent to government debt.

Some problems associated with Aschauer's paper need to be noted. The statistical work is based on level data. The error structure problem emphasized by Plosser and Schwert may not be serious according to the value of the DW statistic. The problem posed by potentially nonstationary data remains and is not clear in its implications. Some more attention, as exemplified by Kormendi, to these troublesome issues would seem desirable. Aschauer's procedure offers, moreover, no sharply focused discriminating test between the neoclassical and the alternative thesis. The Euler equation supplemented with lagged deficits [i.e., Eq. (13)] hardly represents the "conventional thesis." The weird pattern of coefficients for $D_{t-1}$ and $D_{t-2}$ contradicts the conventional thesis. The subsequent test based on Eq. (15) and (16) with their cross parameter properties thus offers at best a test of the neoclassical proposition against an uninterpreted class represented by the augmented Euler equation excluding the conventional thesis. 
3.3.e. Plosser. Plosser's examination of the Ricardian thesis addresses an entirely different dimension than the previous three papers. His paper investigates the implication of the Ricardian hypothesis bearing on assetmarket patterns. A temporal reallocation of taxes expressed by a corresponding accumulation or decumulation of debt does not affect asset prices and interest rates under the Ricardian hypothesis. The basic idea is implemented in the spirit of a neoclassic analysis. Market efficiency or rational expectation is combined with the expectations hypothesis of the term structure of interest rates. This analytic foundation implies a relation between the surprises in holding period yields of securities with different maturities and corresponding surprises in fiscal or monetary magnitudes:

$$
H_{t+1}-E H_{t+1}=B\left[X_{t+1}-E X_{t+1}\right]+v_{t+1} \text {, }
$$

where $H_{t+1}$ is a column vector of holding period returns from $t$ to $t+1$ of bonds of various maturities, $E$ refers to the expectational magnitude, $B$ is a matrix conformable with the dimensions of the vectors $H$ and $X$; the latter vector contains the relevant fiscal and monetary variables. These variables refer in this specific case to the debt monetized by the central bank-the government debt held by the public and government purchases of goods and services. $v_{t+1}$ denotes a random vector.

The neoclassical position implies that an unexpected increase in government purchases raises interest rates and thus lowers holding period returns. This implication is compatible with Keynesian or monetarist analysis. The underlying analysis, however, attributes the result in each case to a somewhat different mechanism. The crucial difference between the neoclassical thesis and the alternative positions, however, surrounds the role of government debt. Surprises in this magnitude yield no consequences with respect to holding period returns under the Ricardian hypothesis. They should produce, in contrast, negatively related consequences under the alternative hypotheses. Lastly, surprises in the monetized portion of the public debt yield, according to Keynesian and (older) monetarist analysis, positively related surprises in holding period returns. Neoclassical analysis is not inherently inconsistent with a nonvanishing effect of monetary surprises. It remains, however, somewhat ambiguous on this point without further specifications bearing on expectations and shock structure. With some dominance of comparatively permanent shocks in the monetary variable, its surprises convey a useful signal value bearing on future inflation. This response mechanism would produce negative reactions in holding period returns to positive monetary surprises. These reactions would, moreover, increase with the maturity of the security under consideration. 
In order to complete the analysis, two analytic building blocks are added. The forecasting equation

$$
X_{t+1}=A(L) X_{t}+u_{t+1}
$$

is introduced with $A(L)$ designating a matrix of polynomials in the lag operator $L ; u$ again refers to a random vector. This formulation advances implicitly an hypothesis about the structure of the process generating the observations of the $X$-vector. Lastly, an expression for $E H_{t+1}$ is derived from the rational expectation theory of the term structure:

$$
E H_{t+1}=R_{\mathrm{l} t}+\phi,
$$

where $R_{1 t}$ refers to a vector consisting only of the current one-period spot rate, and $\phi$ is a vector containing the marginal increments of liquidity premia associated with different maturities beyond the spot rate. Plosser also offers an alternative interpretation of $\phi$ based on the Sharp-Lintner capital-asset model. In this case $\phi$ would be equal to a $\beta$-vector multiplied by the difference between the expectation of a holding period yield for a market basket and the certain current spot rate $R_{1 r}$.

The first step in the empirical examination evaluates the joint hypothesis about market efficiency and the term structure. The implication that current surprises of holding period returns are independent of past observations on money, debt, and government purchases is tested with a suitable regression. The results are quite unambiguous and support the joint hypothesis. A second step in the procedure explores the statistical results bearing on the matrix of coefficients $B$ in Eq. (16). Holding period returns for four different maturities are investigated. In two cases the coefficient estimate of the debt variable is less than its standard error. One coefficient estimate is significant at the 10 percent level, and the fourth coefficient estimate, slightly exceeding its standard error, occurs with a significance level above 10 percent. All coefficient estimates associated with the debt variable are positive. The signs are thus inconsistent with the "conventional analysis." The significance levels confirm, on the other hand, the null hypothesis expressed by the neoclassic thesis. Sign and significance level together yield a clear rejection of the "conventional hypothesis."

The coefficient estimates of the monetary variable also support some version of the neoclassic thesis. Their signs, with the exception of the security with the shortest maturity, are, however, consistent with the "conventional analysis." Only one out of four coefficients reaches a significance level of at most 10 percent. The sign and the confirmation of the null hypothesis obviously provide no support for the supplementary 
hypothesis bearing on the signal effect of monetary surprises in the context of a specific shock structure mentioned above. The coefficient estimates associated with government purchases provide some support for the occurrence of an effect. All estimates exhibit the sign implied by the hypothesis. Two of the four estimates are significant at the 5 percent level and one at the 10 percent level. The significance level for holding period returns on the longest maturity rises beyond 10 percent. We also note the significant estimates for the constant parameter in the regression. This confirms the occurrence of a liquidity premium or the operation of a nonvanishing $\beta$-factor on government securities.

The interpretation of the test deserves some attention. This issue may be usefully addressed with the aid of a somewhat more explicit characterization of the test procedure. The following pair of propositions control the test:

$$
F \supset[M E \cdot E H T S \cdot N C H \supset T], \quad F \supset[M E \cdot E H T S \cdot C H \supset-T] .
$$

$F$ refers to a sentence presenting the hypothesis summarized in the forecasting equation; $M E$ denotes a sentence advancing the market efficiency hypothesis, and EHTS denotes a hypothesis about the term structure of interest rates; $\mathrm{NCH}$ and $\mathrm{CH}$ refer to the alternative hypothesis-that is, the neoclassical and the conventional. Lastly, $T$ refers to the test statement about the $B$ coefficients under the null hypothesis. The crucial point to be addressed here is the conditionality of the test relative to the untested hypothesis contained in $F$. The compelling force of any confirmation or disconfirmation of $T$ depends decisively on the assumption made about $F$. Suppose $F$ is true and $M E \cdot E H T S$ and $T$ are confirmed. We can effectively discriminate under the circumstances and conclude that $\mathrm{NCH}$ is confirmed and $\mathrm{CH}$ disconfirmed. But suppose that $F$ is false. The logical relations between the various sentences offer in this case no grounds to discriminate between $N C H$ and $C H$ on the basis of tests bearing on $T$. With the truth of $F$ given, and $M E \cdot E H T S$ confirmed independently, the confirmation of $T$ must disconfirm $\mathrm{CH}$ and can confirm $\mathrm{NCH}$ in order to satisfy the truth of the whole conditional proposition. Should $F$, on the other hand, be false, then the whole conditional is true irrespective of our decision about $\mathrm{NCH}, \mathrm{CH}$, and $T$. The truth of the conditional imposes under the circumstances no constraint on confirmation or disconfirmation of $\mathrm{NCH}$ or $\mathrm{CH}$ relative to any given decision about $T$. The falsehood of $F$ implies that the test is irrelevant and uninformative. It follows that in the absence of any information about $F$ the results of the test cannot be assigned substantial weight.

One procedure designed to raise the informativeness of the test involves repetition with a variety of different forecasting equations. Plosser's paper moves in this direction. The test is repeated with a forecasting equation 
including current bond-market information. The results bearing on government purchases appear somewhat sharpened. The other results are essentially unchanged. We may conclude that Plosser's paper does not essentially modify the balance of evidence summarized above. It did, however, usefully direct our attention to an alternative dimension-the financial markets and the corresponding opportunities for systematic future examinations of the neoclassic thesis.

3.3.f. Bernheim-Shleifer-Summers and Boskin-Kotlikoff. Two papers recently appeared in the professional circuit that appear to shift the balance of evidence somewhat against the hypothesis of debt neutrality. Both papers move beyond the macro data applied to an examination of consumers' behavior. They exploit in very different ways some micropatterns systematically related to the relevant analysis. The first paper, by Bernheim, Shleifer, and Summers (1985), seems particularly noteworthy. It starts with the observation that most of the existing wealth was transmitted by the prior generation. We noted in a previous paragraph that an "accidental transfer" hypothesis without any bequest motive could explain the occurrence of bequests in a non-Ricardian world. This explanation would probably hold even with an availability of annuities. But it seems doubtful that this hypothesis can explain the order of magnitude of the bequests. The crucial contribution made by BSS (i.e., the three authors) emerges from the explicit construction of a detailed ("nonRicardian") hypothesis explaining the occurrence of bequests that incorporates a bequest motive. This hypothesis, in spite of the acknowledged bequest motive, yields radically different implications from Barro's hypothesis. The explicit specification of this alternative bequest hypothesis offers opportunities for new and richer critical evaluations with untapped data.

The "exchange motivated bequests" hypothesis involves a simple idea developed with a subtle analysis. The idea applies the basic REMM (resourceful, evaluating, maximizing man) model to the interactions between older and younger persons. The hypothesis thus rejects Barro's assumption that older persons are concerned about the future consumption opportunities of their descendants. Older generations accumulate wealth in tradeable (i.e., bequeathable) form in order to purchase services from the younger generation. The services bought by the prospect of bequests occur essentially in the form of attention extended by the younger to the older. An implicit exchange transaction of potential wealth for current attention determines the evenutal wealth transfer from older to younger.

The authors structure their analysis with two sets of utility functions and a set of constraints describing wealth accumulations over time. The utility functions represent the agents in the interacting groups. The expression 


$$
\sum_{t=S}^{\infty} \beta^{t-s} P(\epsilon, t) U_{t}\left(C_{t}, a_{t}\right)
$$

describes the utility function of the testator, where $\beta$ is a discount factor, $P(s, t)$ is the probability of survival from the initial period $s$ to period $t$ and $U_{t}$ is the instantaneous utility as a function of consumption $C_{t}$ and the attention vector $a_{t}=\left(a_{1 t} \cdots a_{n t}\right.$. This attention vector describes the degree of attention extended to the testator by each of the $N$ members of the set $A$ of "credible" beneficiaries addressed by the testator. The latter's utility increases with $C_{t}$ and $a_{t}$. He is also assumed to have a finite deterministic life span $T$ so that $P(s, T+1)=0$.

The utility function of the $N$ beneficiaries is given by

$$
\sum_{t=s}^{\infty} \beta_{n}^{t-s} U_{n t}\left(C_{n}, a_{n t}\right)
$$

We need only comment here that BSS assume beneficiaries to live forever. This assumption simplifies matters with no loss in relevant substance. $U_{n}$ has a positive derivative with respect to $C_{n, t}$ and a negative derivative with respect to $a_{n, t}$. Attention is valued quite differently by the two sides of the exchange.

Expressions (20) and (21) introduce descriptions of wealth accumulations.

a. $w_{t+1}=\left(W_{t}-C_{t}-A_{t}\right)\left(1+r_{t}\right)+A_{t}\left(1+\rho_{t}\right)$,

b. $\quad B_{t}=W_{t}-C_{t}-A_{t}$.

The first applies to testators, with $W$ designating wealth, $A$ the annuity investment made, $r$ the market rate of interest, $\rho_{t}$ the rate of return on $A$, and $B=\sum_{n} b_{n}$ the total sum of bequests; $b_{n}$ is the component of $B$ going to beneficiary $n$. Formulation (a) holders in case the testator survives, and (b) holds in the case of death during the period.

$$
W_{n, t=1}=\left(W_{n, t}-C_{t}+b_{n, t} I(t-1)\right)\left(1+r_{t}\right) .
$$

Expression (21) supplies the condition for beneficiary $n . I(t)=1$ in case the testator dies during the period; otherwise it is zero.

The structure of the strategy game between testators and beneficiaries has now been defined. The testator invests in bequeathable wealth in order to induce attention from potential beneficiaries, and the latter compete with attention for bequests. BSS develop a clever and intricate argument to determine a (Nash) solution to this game. A general sense of the detailed argument will suffice here. The testator chooses an optimal plan $\left(C,{ }^{*} a, b_{1}^{*}, \ldots, b_{N}\right)$ for consumption, attention, level, and distribution 
of bequests. Optimization proceeds subject to the constraints, including a feasibility condition. The latter imposes that the choice of $\left(a, b_{1}, \ldots, b_{N}\right)$ must be confined to a range assuring to beneficiaries at least a utility equal to nonparticipation in the game (i.e., $a_{n}=b_{n}=0$ ). The beneficiaries may be interpreted to play a subgame conditioned on the vector $\left(b_{1}^{*}, \ldots, b_{N}^{*}\right)$. The testator can, of course, not impose his optimal choice of attention on beneficiaries. He thus faces a problem of selecting a bequest rule-that is, a vector function $b(H, B)$, where $H$ denotes the history of the game and $B$ the total level of bequests-that induces beneficiaries to supply $a^{*}$ voluntarily in their own interests. BSS show the existence of a specific rule in situations with at least two beneficiaries. This rule does produce a Nash equilibrium solution $\left(a^{*}, b^{*}\right)$. This equilibrium implies that the testator fully appropriates the surplus utility created by the exchange. The Ricardian equivalence theorem fails to be satisfied under this "exchange motivated bequests" hypothesis. Bequests do occur and they are motivated. They are, however, not motivated by the future welfare of descendants but by the purchase of current attention. A debt-financed deficit yields, in general, under the circumstances, no offsetting intergenerational transfers and personal saving. Opportunities are modified and real variables change.

An extensive empirical evaluation follows the analytic argument. The hypothesis implies that parents influence their children's behavior by holding wealth in bequeathable forms. It implies, in particular, that contacts between parents and children within families with bequeathable wealth are more extensive. The authors exploit the data from a longitudinal retirement history survey. They especially derive data on bequests $b$ and contacts. A normalized measure $V$ of contacts per child is constructed with the raw data. An OLS regression of $V$ on $b$ yields the "proper sign" but does not confirm the hypothesis. The authors trace this negative result to potential endogeneity of $b$. The hypothesis does imply that $b$ and $V$ are simultaneously and interactingly determined. A TSLS procedure thus corresponds better to the structure of the hypothesis. The results are dramatically different in this case. The null hypothesis of no effect on $b$ on $V$ can be rejected with high confidence. A special test assessing the exogeneity of $b$ supports the choice of a TSLS procedure. Exogeneity of $b$ can also be rejected with substantial confidence.

The authors recognize that consistency of the empirical pattern with the hypothesis cannot exclude other possible explanations. They evaluate a variety of such alternatives in order to strengthen support for the hypothesis advanced. They consider thus the possibility that influences emanating from several omitted and personal dimensions are erroneously attributed to $b$. The effect of $b$ on $V$ survives this examination. Some alternative explanations of the observed correlation between $V$ and $b$ do 
not distinguish between wealth in bequeathable and in nonbequeathable forms. The hypothesis advanced assigns, in contrast, no significance to the latter. The statistical results again confirm the hypothesis under examination. The case for alternative hypotheses emphasizing the role of the cost of contacts imposed on children or of the parents housing wealth fails similarly when confronted with relevant data. Other implications are also exploited in order to extend the range of relevant observations bearing on the hypothesis. Lastly, data on the comparatively low frequency of privately purchased annuities or of gifts offer some useful information. BSS discriminate, with their help, between the hypothesis considered, the "accidental bequest" hypothesis discussed in a previous section, the "bequests for their own sake" hypothesis, and the "intergenerational altruism" hypothesis. The authors' hypothesis also survives this last round of assessments. A careful reader of this paper may agree that the wideranging and imaginative empirical evaluation establishes a serious case on behalf of the hypothesis that bequests are a component of an exchange. The relevant and pervasive occurrence of such transactions is, moreover, inconsistent with the Ricardian thesis of debt neutrality.

A serious limitation of prior studies bearing on the Ricardian thesis is their concentration on macro data of consumption patterns. BSS substantially enriched our assessment by exploring a wider range of implications requiring micro data. Boskin and Kotlikoff (1985) pursue a similar course in an investigation that required a massive labor and computational input. Their examination addresses an important implication of the Ricardian hypothesis expressed by the intergenerational altruism model. Under this hypothesis consumption expenditures depend only on "collective resources" representing the real underlying situation. It implies, in particular, that consumption does not depend on the age distribution of the population. The analysis is based on a present value of family utility. This formulation involves a series of instantaneous utility functions specified for all descendants and their respective age groups. A description of wealth accumulation for both household and government serves as a constraint on the optimal choice for an intertemporal consumption pattern of the "infinitely living" family. The first-order condition determines an expression within the usual family of Euler equations relating consumption in adjacent periods. The problem, however, allows no tractable analytic solution describing consumption as a function of predetermined magnitudes. The authors thus pursue with great patience a different course. They solve a finite-period approximation to the infinite optimization problem. The approximation is chosen so as to lower changes in the optimal consumption pattern produced by extending the period to a negligible level. The data set used covers the period 1946-81. A dynamic programming approach is applied to compute the solutions for the relevant 
sample period. It should be noted that this optimal pattern $\bar{C}$ is derived in the context of stochastic uncertainty about future rates of return and earnings. The derivation, moreover, depends on a specific utility function and an age-weight assigned to age-group instantaneous utilities. The authors actually investigate combinations of parameters (of instantaneous utility and the discount factor) in order to find the selection that determines for $\bar{C}$ the closest fit (in terms of root mean squares) to the data.

The test is performed with a regression of actual consumption $C$ on $C$ and five age groups expressed in terms of their respective income shares. They hypothesis of intergenerational altruism,

$$
C=\beta_{0}+\beta_{1} \bar{C}+\lambda_{1} s_{1}+\cdots \lambda_{5} s_{5}+\epsilon,
$$

implies that $\lambda_{0}=\lambda_{i}=0$ for $i=1, \ldots, 5$ and $\beta_{1}=1$. The statistical inference confirms the last condition but disconfirms the others. The pattern of $\lambda$-coefficients seems consistent with some life cycle hypothesis. The coefficient pattern estimated implies, in particular, that a redistribution of 10 percent of income from the younger to the older generation would raise consumption by 1 percent and lower the net national savings rate by 9 percent.

The authors' preliminary capital and labor-intensive investigation clearly disconfirms the Ricardian thesis couched in terms of an "intergenerational altruism" hypothesis. This disconfirmation must be substantially qualified, however. The test does not uniquely address this crucial hypothesis. It is mixed with an array of auxiliary hypotheses bearing on the choice of utility function, age-weight assignments, the specification of uncertainty, and other components. The disconfirmation could, of course, apply to the set of auxiliary hypotheses. This comment does not lower the value of a major piece of work developed by Boskin and Kotlikoff. Their examination does reenforce the results obtained by BSS, and further research involving variations in the choice of auxiliary hypotheses may confirm the rejection of the Ricardian thesis.

\subsection{A neoclassical analysis of government expenditures}

The Ricardian theme does not imply irrelevance of fiscal policy. Expenditures and taxes remain potent instruments shaping output, employment, and welfare. Barro $(1981 \mathrm{~b}, 1984)$ also initiated in this field the neoclassical explorations. The general analysis of fiscal policy uses the same market-clearing approach so extensively exploited in monetary analysis.

Barro's discussion of fiscal policy moves incisively beyond the sinkhole theory of the government's operations. The private-sector output acquired by the public sector forms the basis for the supply of public con- 
sumption goods to households and productive input services to private producers. "Public consumption" competes to some extent with private consumption. A parameter, $\alpha$, summarizes this fact. It expresses the marginal rate of substitution between public and private consumption. With $\alpha=1$, "public consumption" and "private consumption" substitute one for one. A vanishing $\alpha$-that is, $\alpha=0$-reflects absence of any substitution between the two types of consumption. With $0<\alpha<1$ a unit increase in "public consumption" lowers private consumption by less than one unit.

The government's supply of productive services raises an input available to private producers. Private-sector output thus expands in accordance with the marginal productivity of this input in private production. A parameter $\beta$ reflects this marginal productivity. The parameter describes the increase in private-sector output produced by a unit increase in government real expenditures. Government real expenditures both fully reflect the public sector's absorption of private output and its supply of goods and services to the private sector. The government sector is made to behave as if it contracted for goods and services produced by the private sector that are immediately made available to private households and producers. It is, moreover, assumed that the government's input services do not affect the marginal product of labor and capital in the private production process.

The system used to analyze the impact of government expenditures and (distortionary) taxes is confined to some basic elements expressed by two equations:

$$
\begin{aligned}
& C\left(\underline{r}, \underline{G}_{1}, \underline{\bar{G}}, \ldots\right)+I(r, \ldots)+G_{1}=Y\left(\underset{-}{r, G}, \underset{+}{G_{1}}, \underset{+}{\bar{G}}, \ldots\right), \\
& M=L\left(r+\pi, \underset{+}{Y}, G_{-}, \cdots\right) .
\end{aligned}
$$

Equation (23) describes the market-clearing condition for the output market. The various symbols have standard meanings: $C=$ private real consumption, $I=$ private-sector real investment, $G_{1}=$ current government real expenditures, $\bar{G}=$ permanent government real expenditures anticipated for a horizon beyond the current period, $Y=$ real income, $r=$ real rate of interest, $M=$ money stock, $P=$ price level, and $\pi=$ expected rate of inflation. The signs below the variables indicate the direction of response of the dependent variable. The two distinct magnitudes for government real expenditures are introduced in order to analyze the impact of transitory and permanent changes in government expenditures. This analysis proceeds initially under the assumption of lump-sum taxes. Distortionary taxes are introduced at a later stage. The path of the 
money stock together with the two government expenditure variables refer to the exogeneous components in the analysis. This implies that $\pi$ is also held fixed in accordance with the path of $M$.

We consider first the impact of a transitory increase of $G_{1}$. A simple diagram (Figure 3.3) is used for this purpose. Line $d$ represents the demand for output occurring on the left side of Eq. (23). Line $s$ marks the supply located on the right of the same equation. An increase in $G_{1}$ against a background of a constant permanent government expenditure implies that some expected future expenditures must fall to offset the temporary rise of $G_{1}$. Constancy of $\vec{G}$ means that the representative real opportunities expressing the households real wealth remains unchanged. These real opportunities are defined by the difference between the present value of future real income and the present value of future government real expenditures.

A constant $\bar{G}$ implies that an increase in $G_{1}$ induces no wealth effect on demand or supply of output. This means, in particular, that $\Delta G_{1}>0$ shifts the demand and supply line in the graph for reasons other than changes in basic real opportunities. The net effect of the impact on output and real interest rates can be easily determined by comparison of the horizontal shifts of the two curves. The supply shifts to the right by an amount $\beta$ per unit change in $G_{1}$, whereas demand shifts by an amount of

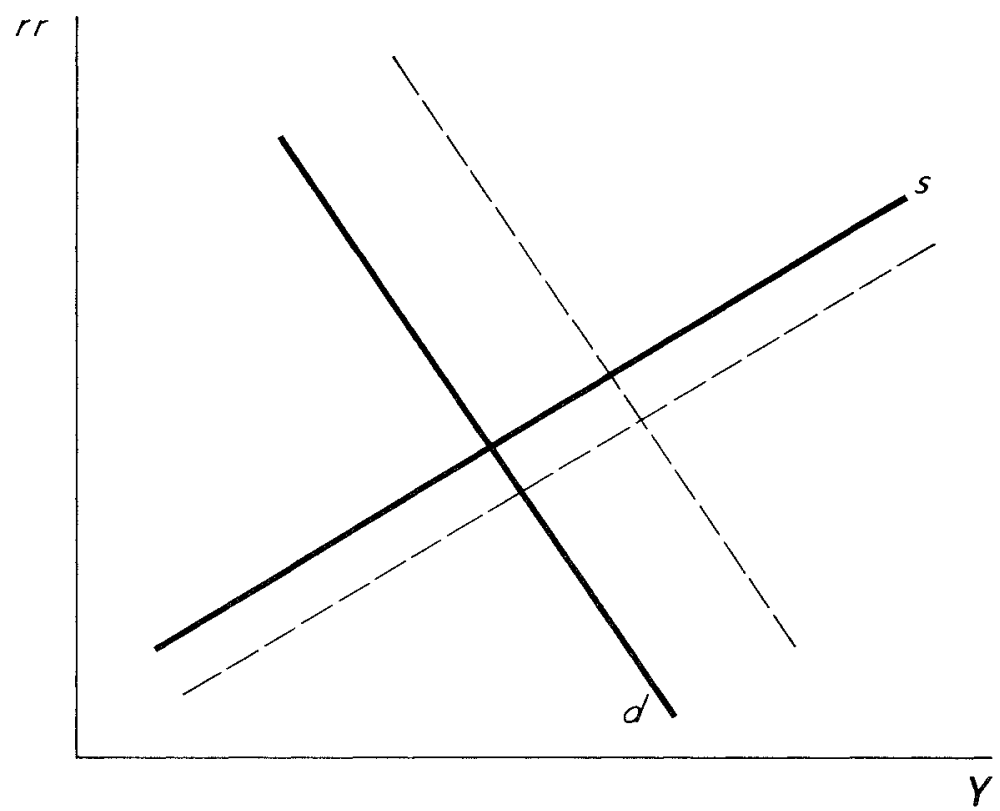

Figure 3.3 
$1-\alpha$ in the same direction. Assuming that $\alpha+\beta<1$, as Barro does, the increase of $G_{1}$ creates an excess demand of $1-\alpha-\beta$ per unit increase at the initial real rate. The market-clearing condition thus forces a rise in the real rate of interest. The simultaneous shift of both curves to the right assures, moreover, that output also rises. We note immediately that we observe, in contrast to a Keynesian analysis, no multiplier effect. The diagram suggests that the increase in output per unit increase in $G_{1}$ is less than $1-\alpha<1$. The economy's response thus imposes a crowdingout effect on both private consumption and investment. Crowding out is, however, avoided with $\beta=1$ and $\alpha=0$.

The solution for $r$ and $Y$ can be inserted into the portfolio equation in order to determine the response of the price level. Before we consider this final result we need to examine the rationale of $G_{1}$ in money demand. $G_{1}$ operates in the nature of an in-kind transfer. It is thus interpreted to lower, relative to $Y$, the household's monetary transactions. The increase in $G_{1}$ thus reenforces the effect of a higher real rate of interest on real balances. The net result thus depends on the comparative strength of the income effect. The price level rises in response to a temporary increase in government expenditures, provided that the effect exerted by $r$ and $G_{1}$ on real balances dominates the income effect. With a dominant income effect, prices fall.

A different pattern emerges under a permanent increase in government expenditures. This requires a simultaneous rise in $G_{1}$ and $\bar{G}$. We need to consider, therefore, the consequences of an increase in $\bar{G}$. Once again we evaluate the shifts in demand and supply of output. We note first that the immediate effects induced by $G_{1}$ expressed by $\alpha$ on household demand and $\beta$ on production do not occur in this case. The increase in $\bar{G}$ with $G_{1}$ constant provides no additional goods or services in the current period. The current impact of $\bar{G}$ operates via wealth and labor effort. A unit, increase in $\bar{G}$ lowers real opportunities of the private sector by one unit, holding $r$ constant. This is modified by future $\alpha$ and $\beta$ effects. The first effect provides additional resources to households, and the second raises the future income stream. Additional modification results from a higher labor supply produced by lower real wealth. This last modification raises real income by an amount $a$. The net wealth decline is thus $1-\alpha-\beta-a$. Barro postulates at this stage a one-to-one relation between changes in real wealth and real consumption. This implies that the average propensity to consume with respect to wealth prossesses a suitable positive derivative with respect to real wealth. The increase in $\bar{G}$ induces no direct effects on investment and $G_{1}$. The total direct-demand effect coincides therefore with the horizontal shift of the consumption function-that is, $-(1-\alpha-\beta-a)$. We combine this shift in aggregate demand due to $\bar{G}$ with the shift due to $G_{1}$ (which is $1-\alpha$ ) and 
obtain $\beta+a$ as the net shift in aggregate demand attributable to a permanent rise in government expenditures. This matches the positive horizontal shift on the supply side, which also equals $\beta+a$. It follows that a permanent expansion of government expenditures raises output with no effect on real rates of interest. The price level effect is algebraically larger than the response produced by a transitory increase in government expenditures. But the price effect still remains ambiguous and conditioned by the comparative strength of $Y$ and $G_{1}$ in money demand. The dominance of $Y$ implies a fall in the price level. Lastly, similar to the case of transitory expenditure increases, there occurs no multiplier effect. The expansion of output $\beta+a<1$ is less than the unit increase in $G_{1}+\bar{G}$. The resulting crowding out is, moreover, concentrated on private consumption.

The impact of tax policies is investigated in a similar vein. A flat-rate tax on income net of depreciation and exemption is introduced. This tax modifies the relevant margins for household and investor decisions. This modification implies that the after-tax real rate of interest and the tax rate appear as arguments in the consumption and supply functions. It follows that an increase in the tax rate offset by expanded exemptions in order to satisfy the government's budget constraint lowers output and real interest rate.

This analysis has been exposed by Barro to some empirical assessment. One evaluation (1984a) traces the broad contours of transitory expenditures. Such expenditures are essentially confined to war episodes and thus emerge for all practical purposes in the nature of military expenditures. The Vietnam episode can be disregarded, since the comparatively negligible magnitude of transitory spending ( 2 percent of GNP) is probably swamped by other influences on real GNP. In contrast, the two world wars and the Korean war episode are quite informative. Transitory spending loomed with substantial force. It is remarkable that aggregate output responded with a fraction of around .55 to .60 to transitory expenditures in all three cases. It is noteworthy, moreover, that crowding out operated dominantly on real investment. These observations appear quite consistent with the implication of Barro's analysis.

A more thorough statistical investigation addressed the relation between aggregate output on the one side and both transitory or permanent expenditures on the other side. The latter two variables were represented by some ingeniously complicated measures, which probably avoid nonstationary characteristics. The nonstationary character of output is attended by the inclusion of a time trend. The results seem remarkably consistent with the implications bearing on the response pattern of output. Transitory expenditures induce a larger impact than permanent expenditures. But the case for even a most modest multiplier effect for transitory spending remains quite weak. Still, larger permanent expenditures do lift aggre- 
gate output permanently above the time trend, but at some cost of private real expenditures.

The results may be sensitive to the range of auxiliary hypotheses guiding the measurement procedures. Further investigations along this interesting approach need to be explored in order to deepen the assessment of a neoclassical fiscal analysis. One particular issue needs our attention in this context. Nelson and Plosser (1982), followed by Stulz and Wasserfallen (1985), demonstrated with extensive tests that the hypothesis of a deterministic trend is overwhelmingly dominated by the hypothesis of a stochastic trend. A stochastic trend usually collapses the stationary component and radically modifies the results of regression analysis applied to it. One suspects that substituting a stochastic trend for the time trend and then regressing the resulting stationary component on transitory and permanent expenditures would substantially alter the outcome.

Some comments should still be addressed to the analysis. The contrast with Keynesian analysis should be noted first. Barro confirms that an essentially price-theoretical approach (Brunner 1970) lowers the significance of interacting multiplying flows. The latter moves into center stage of the analysis once we proceed on the assumption of given price level or nominal wages. A "non-market-clearing" analysis typically converts fiscal actions into a multiplier effect on output. This effect is produced by variations induced in aggregate demand encountering unresponsive prices. Barro's neoclassical approach differs radically from the Keynesian tradition. Fiscal policy is analyzed in the context of full information and market clearing. This context would prevent any real effects of monetary shocks. This environment does not preclude temporary and permanent real responses to fiscal actions. These responses, however, depend crucially on the properties of output supply. The supply responses fully determine the output effect of permanent expenditure increases. We also note the emphasis on changing output composition produced by fiscal action associated with the "crowding out" of private consumption and investment. The difference in this respect between temporary and permanent fiscal action is also significant. This result cannot be reproduced within the standard IS/LM framework.

There remains a question bearing on the interpretation of this analysis. The full information market-clearing approach describes, in my judgment, a benchmark forming a "gravitational center" of economic processes approximating long-run aspects. Two important revisions would probably move us somewhat closer to reality in some sense without sacrificing Barro's basic price-theoretical thrust. The prevalence of incomplete information needs to be recognized, and a more general concept of market clearing needs to be used. This concept acknowledges that prices do not 
reflect all ongoing shocks. They will rationally reflect perceived permanent shocks but not (perceived) transitory shocks. There will be a market clearing under the circumstances relative to (perceived) permanent shocks but not with respect to all shocks. Some shock-absorbing buffers thus operate in the economy and distribute the output adjustment to shocks over time. This pattern would probably produce a more substantial difference between the effects of temporary and permanent expenditure changes.

A representative work of neoclassical analysis in the new mode was recently developed by Aschauer and Greenwood (1985). The analysis is built in a dynamic choice-theoretic context. A representative household optimizes over two periods subject to a constraint that incorporates tax parameters affecting labor income in either period and a tax parameter imposed on the second period's capital income. Market-clearing conditions are added for each period. These conditions reveal on the supply side the structure of production; that is, investment in the first period adds to output in the second period. The first-order optimality condition together with the market-clearing condition determines the system of equations used to examine the impact of fiscal policy. A budget constraint for the government sector with a "Ricardian thrust" assures a consistent pattern of fiscal action. Moreover, the government provides, similar to Barro's case, consumption goods to households and input services to private producers. The households' utility function depends, moreover, on total consumption available to the household, which is the sum of private consumption and the weighted government contribution with weight less than unity. This weight again represents the marginal rate of substitution between the two types of consumption.

The analytic structure is applied to an examination of tax policies, stabilization policy with the aid of adjustable tax parameters, expenditure policies, and optimal taxation. An increase in the second period's (flat) tax rate on labor income induces intertemporal substitutions that raise the first period's labor supply and investment, but lower the second period's labor supply. The welfare effect of this tax increase depends crucially on the occurrence of distortionary taxes. Welfare falls when first-period income is untaxed. Welfare rises, however, in case first-period income is already taxed. The new tax modifies to some extent the intertemporal distortion of the first tax.

The consequences of stabilization policy are explored under the assumption that the production process in the second period is subjected to random shocks. The larger their variance, the lower the representative households' welfare level. But a stabilization policy operating with a state-contingent tax parameter actually lowers the welfare level. However, uncertainty due to stabilization raises current consumption and decreases current work effort, output, and investment. 
A temporary (unexpected) increase in first-period government expenditures (expressed by a linear combination of consumption and productive services) lowers welfare, provided the marginal product of government productive services and the marginal rate of substitution between private and public consumption is less than unity. Work effort in both periods increases, whereas investment declines. Output rises in the first period and falls in the second period.

An anticipated increase in the second-period government expenditures raises first-period investment and work effort in both periods. The consequences of a permanent increase in government expenditures follow from combining the prior two cases. Work effort and output rise in both periods, and consumption declines.

Aschauer's (1985) elaborate analysis produces results somewhat similar to Barro's investigation. The argument also proceeds on the basis of full information and continuous full-market clearing. There is, however, no money and, thus, no price level in the model. The choice-theoretic foundation prevents simply adding a money demand equation. Money would have to be added to the utility function or embedded in a production or exchange constraint (Brunner 1951). The usual homogeneity conditions can, however, be expected to be satisfied. Aschauer's results probably carry over to a monetary economy. Finally, an examination of the detailed structural knowledge required for stabilization and optimal tax policy reveals the dubious relation between such analysis and actual policy issues. This aspect will be reconsidered in the last section of the paper.

\section{Deficits, Monetary Regimes, and Economic Activity}

\subsection{The endogenous states of the monetary regime: Sargent and Wallace}

The "stability problem" associated with deficit finance revealed an interrelation between fiscal and monetary regimes. This issue surfaced again in recent years, but in a modified context. Thomas Sargent and Neil Wallace (1982) approached the interrelation between the two regimes, or the financial coordination problem, with a concern directed to a very different issue. They question the long-run survival of an anti-inflationary monetary regime when confronted with persistent deficits sufficiently large to raise the real stock of government debt relative to real national product. The problem may be explored with the aid of the government's budget constraint: 


$$
\stackrel{\circ}{S}+\stackrel{\circ}{B}=G+T R-T A+i S,
$$

where $S$ denotes the stock of publicly held debt, $B$ is the monetary base, $G$ refers to nominal government expenditures on goods and services, $T R$ designates transfer payments, and $T A$ designates tax revenues; $i$ should be interpreted as the average interest rate on outstanding debt. The budget equation can be translated into the following expression:

$$
\begin{aligned}
\stackrel{\circ}{s} & =\overline{\operatorname{def}}+\left[(r r-n)+\left[n-\frac{\Delta y}{y}+\left[\pi-\frac{\Delta p}{p}\right]\right]\right] \\
& -\left[(\pi+n)+\left[\frac{\Delta p}{p}-\pi\right]+\left[\frac{\Delta y}{y}-n\right]\right] b-\stackrel{o}{b},
\end{aligned}
$$

where $s$ describes the ratio of real debt to real national income. $b$ similarly represents the volume of base money per unit of nominal national income (i.e., it is the reciprocal of base velocity), def consists of the basic deficit ratio expressed as

$$
\overline{\mathrm{def}}=\frac{G+T R-T A}{Y},
$$

with $Y$ indicating nominal national product. The other symbols are $r r=$ real interest rate, $n=$ normal rate of real growth, $y=$ actual output, $\pi=$ expected rate of inflation, and $p$ is the price level.

Expression (26) may be considered as a differential equation in $s$. A stable process requires that the bracketed expression associated with $s$ on the right side be negative. Actual real growth $\Delta y / y$ and actual inflation $\Delta p / p$ sufficiently large would produce a negative sign. But this state is purely transitory. Over the long run relevant for this investigation the sign would be determined by $r r-n$, the relation between the real rate and the normal growth rate. This relation appeared with a major role in traditional growth theory. It implicitly occurs also in the analysis surrounding infinite intertemporal budget constraints. The arguments bearing on the Ricardian thesis require, in particular, that $r r>n$. A real rate $r r$ exceeding the normal real growth $n$ is a necessary condition for the Ricardian thesis. Government debt would appear as net wealth under the opposite inequality. However, the inequality $r r<n$ raises subtle issues about its relevant occurrence in a steady-state context. A major problem is the reconciliation of finite assets values with $r r \leqslant n$. Such reconciliation could possibly be achieved in a model combining "intergenerational selfishness" with uncertainty of death (Blanchard 1984). This combination would determine a discount rate exceeding the real rate of interest. 
The relevant long-run relations may now be written as

$$
\stackrel{\circ}{s}=\overline{\operatorname{def}}+(r r-n) s-(\pi+n) b .
$$

We note that a steady-state condition also requires that $\stackrel{o}{b}=0$. This expresses the fact that the price level is fully adjusted at any time to the prevailing volume of the monetary base, and $b$ is fully adjusted to the ongoing inflation. Under the first state-that is, $r r>n$-consistent with the Ricardian thesis, the debt-deficit process is unstable. For any initial value $\stackrel{0}{s}>0$ the real debt ratio will persistently rise with the persistence of deficits def and low inflation. According to the Ricardian thesis, such a state does not persist. The temporal distribution of taxes implies that a stream of positive deficits over the nearer future will definitely be offset by higher taxes and negative deficits in the wider future. We should clearly recognize here the structure of the argument. A predetermined path of deficits def excluding "inflation taxes" proceeds in a "Ricardian World." The infinite intertemporal budget constraint thus imposes eventually an increase in taxes. But the predetermined characters of def and, implicitly, of ordinary taxes means that the inflation tax remains as the only possible adjustment to satisfy the infinite budget constraint. It thus follows that a noninflationary policy cannot be maintained over time in the context of a permanent deficit that is sufficiently large.

The infinite budget constraint reveals the nature of the problem. The single-period constraint

$$
G_{t}+S_{t-1}\left(1+i_{t-1}\right)=T_{t}+S_{t}+B_{t}-B_{t-1}
$$

can be assembled into an intertemporal expression in terms of real magnitudes per unit of real income

$$
\sum_{t=0}^{\infty}\left[\frac{1+n}{1+r r}\right]^{t}\left(g_{t}-t_{t}\right)+s_{0} \frac{1+r r}{1+n}=\sum\left[\frac{1+n}{1+r r}\right)^{t} \frac{\Delta B_{t}}{B_{t}} \frac{1}{V},
$$

where $V$ is the velocity of the monetary base. Once the left side is fixed at a substantial positive level, it follows that a very low growth of $\Delta B / B=\pi$ over an initial segment must be followed by larger monetary growth in the future.

The argument presented by Sargent and Wallace can be reconstructed along the following lines, using expression (30) above. The stock of real debt per unit of real income at time $N$ satisfies

$$
s(N)=s_{0}+[\overline{\operatorname{def}}-(\pi+n) b] \frac{\exp (r r-n) N}{r r-n} .
$$


Under the assumption that $\overline{\operatorname{def}}>(\pi+n) b$, the stock $s$ grows monotonically with time $N$. Sargent and Wallace simply state that there exists ultimately a limit for $s$ (somehow). The higher the levels reached by $s(N)$ the greater must be the subsequent inflation. This follows again from expression (29). Once an upper limit $\bar{s}$ is imposed with an unchanged def, the inflation rate must adjust in accordance with

$$
\bar{\pi}=\frac{\overline{\mathrm{def}}}{b}+(r r-n) \frac{\bar{s}}{b}-n .
$$

The positive relation between $\bar{\pi}$ and $\bar{s}$ is immediately obvious. A persistent accumulation of the real debt burden can ultimately always be terminated by sufficiently high levels of inflation.

Expression (32) can be used with two different interpretations according to the nature of the inequality between $r r$ and $n$. With $r r>n$ it describes the inflation rate required to satisfy an imposed stock of relative real debt $s$. Alternatively, with $r r<n$ it determines the equilibrium stock $s$ associated with any predetermined inflation rate; that is

$$
s=\frac{\overline{\mathrm{def}}-(\pi+n) b}{n-r r} .
$$

In the first case fiscal and debt conditions dominate monetary policy, and in the second case monetary policy dominates the debt position.

The difference between the two states involving the nature of the adjustment to a constant real debt ratio $s$ can be outlined in terms of Figure 3.4 .

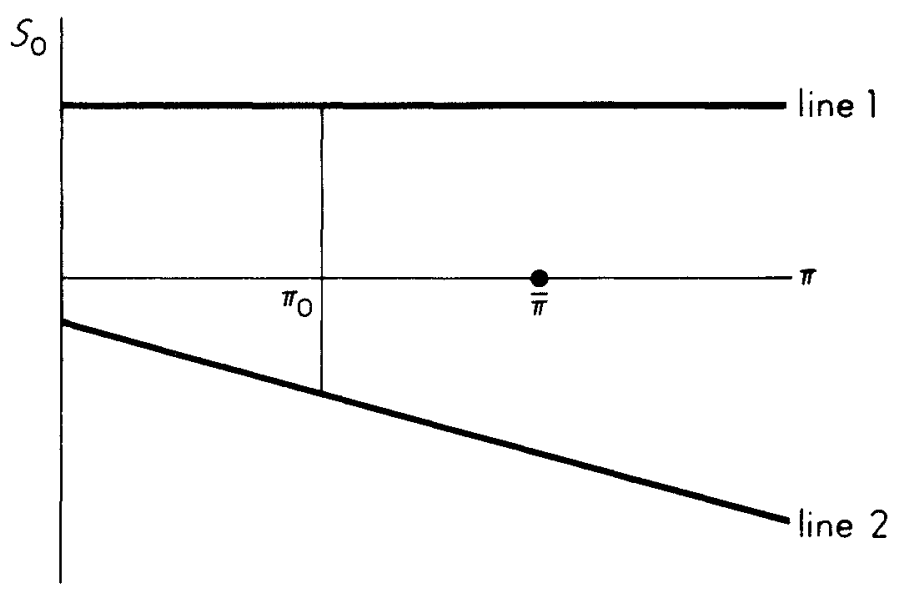

Figure 3.4 


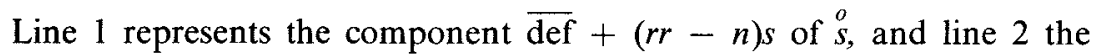
component $[-(\pi+n)] b$. Now consider the first state with $r r>n$ and an inflation rate $\pi_{0}$ below the inflation rate $\bar{\pi}$ required to hold $s$ constant. This means that the vertical distance between line 1 and the $\pi$-axis exceeds the vertical distance between the $\pi$-axis and line 2 . The rate of change of $s$ is positive under the circumstances, and line 1 drifts higher. This drift continues so long as the basic deficit $\overline{\text { def }}$ is maintained and $\pi_{0}$ is less than $\bar{\pi}$ [Eq. (32)]. In order to stablize the real debt ratio $s$, the inflation rate must be raised to the required rate $\bar{\pi}$, which rises with $s$. The higher line 1 was allowed to drift up, the further out to the right shifts $\bar{\pi}$.

In the second state characterized by $r<n$, the real debt ratio $s$ adjusts, in contrast, to any predetermined level $\pi_{0}$. Suppose the initial condition is again described by the graph. The real debt ratio $s$ rises under the circumstances, and this lowers because $r r-n<0$, line 1 . This process persists until the vertical distance between line 1 and the $\pi$ axis coincides with the vertical distance between the $\pi$-axis and line 2 .

Darby's (1984) rebuttal of the problem addressed by Sargent and Wallace concentrates essentially on the stability of the process and some observations supporting the required inequality. But the stability hardly removes the central issue brought to our attention by Sargent and Wallace. The following table reveals the problem. We are shown the equilibrium real debt ratio associated with various basic deficit ratios under a stable process.

$$
\begin{aligned}
& \begin{array}{cc}
\overline{\mathrm{def}} & s \\
\hline 01 & 40
\end{array} \\
& .05 \quad 2.40 \\
& .14 .90 \\
& \pi=0, \quad b=.05, \quad r r=.02, \quad n=.04
\end{aligned}
$$

The assumptions made with respect to $\pi, b, r r$, and $n$ are listed below the table. A glance at the table indicates that deficits of the order experienced or still expected in the United States and Europe would eventually produce, even in the context of a stable process, a massive increase in the real debt ratio from the current U.S. level of about .35. We should be reminded that this massive relative expansion of the government debt would occur in the context of a "non-Ricardian" world defined by $r r<n$.

Important real consequences emerge under the circumstances. Real rates of interest rise, and output is shifted from investment to consumption. Normal growth will consequently decline. The negative difference $r r-n$ may thus disappear, and the economy may move into an unstable debt accumulation process. The smaller (absolutely) the initial negative difference $r r-n$ and the larger the permanent deficit with the implicit 
equilibrium real debt ratio, the greater is the likelihood of a change in the sign of the crucial inequality.

The shift from $r r-n<0$ to $r r-n>0$ does not mean that the system necessarily assumes a "Ricardian property." The change in inequality is certainly consistent with such a property. It need not occur, however, because the inequality forms just a necessary condition for the Ricardian equivalence to occur. Persistence of a "non-Ricardian" world under the condition $r r>n$ aggravates, of course, the real consequences outlined above. These consequences especially induce the persistent rise of interest rates and the real debt burden. They eventually determine responses in the political arena that initiate an inflationary regime.

We should note that this argument is consistent with the monetarist and Keynesian analysis of the financial consequences associated with a budget deficit discussed in Section 2.3. The "monetarist" framework used 12 years ago for this purpose can easily be applied to the current problem. This common argument contrasts, however, with the argument attributed above to Sargent and Wallace in order to obtain the same result. The infinite budget constraint is made to impose the eventual inflationary solution. The Sargent-Wallace analysis suffers, however, from a troublesome indefiniteness associated with the arguments centered on infinite intertemporal budget constraints. The latter only conveys to agents that taxes must be adjusted some time at an indeterminate future in order to obey the constraint. The economic or social mechanism eventually producing the shift from debt finance to inflationary remains, moreover, quite obscure. A "Ricardian world" does not seem to provide such a mechanism. Sargent and Wallace suggest in passing the operation of limits of demand for securities. But such "limits" would be reflected in rising real interest rates and thus violate the "Ricardian pattern." The implicit indefiniteness in the world described by Sargent and Wallace means that agents are confronted with a substantial uncertainty with respect to timing, magnitude, and variance of the inflation tax.

This uncertainty is not recognized by the "Ricardian model." The resulting purchasing power risk associated with nominal bonds produces a risk premium represented by a covariance term (Baghat and Wakeman 1983 ) in the standard capital-asset pricing model. This risk premium is added to the basic (risk-free) real rate of interest to form the effective real rate. Considerations of uncertainty operating in the context of an infinite intertemporal budget constraint thus move the analysis beyond a "Ricardian world." The uncertain temporal reallocation of taxes produces real consequences affecting agents' real opportunities.

A cautionary note must be added. Once we abandon "nonlumping" taxes, the relevant real rate $r r$ should be net of taxes on interest payments or receipts. Second, the relation between $r r$ and $n$ needs to be more care- 
fully rephrased in order to avoid a relation between a risky return expressed by $n$-most especially once we acknowledge the relevance of a stochastic trend (Nelson and Plosser 1982; Stulz and Wasserfallen 1985), and a possibly riskless return to represent $r r$.

It was argued above that the stability of the debt process-that is, the sign of the difference $r r-n$-does not address our crucial problem raised by Sargent and Wallace. The crucial problem is the long-run danger of permanent inflation at a potentially massive scale.

The next table covering both states summarizes the long-run inflation threat associated with persistent deficits. The inflation rate is computed under the condition that the real debt

\begin{tabular}{|c|c|c|c|}
\hline \multirow{2}{*}{\multicolumn{4}{|c|}{$\begin{array}{c}s=.33, b= \\
.06=r r>n=.03\end{array}$}} \\
\hline & & & \\
\hline $\operatorname{def}$ & $\pi$ & def & $\pi$ \\
\hline .01 & $39 \%$ & .01 & $10 \%$ \\
\hline .05 & $139 \%$ & .05 & $90 \%$ \\
\hline .10 & $239 \%$ & .10 & $190 \%$ \\
\hline \multicolumn{2}{|c|}{$.06=r r>n=.03$} & \multicolumn{2}{|c|}{$.02=r r<n=.03$} \\
\hline def & $\pi$ & def & $\pi$ \\
\hline .01 & $50 \%$ & .01 & $7 \%$ \\
\hline .05 & $150 \%$ & .05 & $87 \%$ \\
\hline .10 & $250 \%$ & .10 & $187 \%$ \\
\hline
\end{tabular}

ratio is held constant either at .33 or .5 . We notice that, irrespective of the stability conditions $r r-n$, the long-run inflation threat embedded in a permanent basic deficit of 5 percent of gross national product would move us to levels not yet experienced as a maintained phenomenon in the United States or Europe.

\subsection{The endogenous state of the monetary regime: a choice-theoretic analysis}

The absence of any motivating force in the account presented by Sargent and Wallace explaining the eventual change in monetary regime directs our attention to McCallum's (1984) paper. The author adapts the model introduced by Sidrauski for his purpose. A representative agent maximizes the present value of current and future (instantaneous) utility over an infinite horizon. Instantaneous utility depends on real consumption and real money balances. Bonds, issued by the government, convey no direct utility to the agent. They do occur, however, in the agents' budget constraint. The agent is, moreover, visualized as a joint consuming-producing 
unit. A simple production technology is thus incorporated in the budget constraint. Maximization proceeds subject to the (infinite) set of these constraints. The first-order conditions yield restrictions on consumption $c$, real balances $m$, the stock of real capital $k$, the Lagrangian variable, and the usual inequality constraint bearing on the real rate of interest and the agent's bond holdings $b$. These conditions are supplemented with the government sector's budget constraint, which provides for finance of the deficit by means of money creation and bond issues. Consolidation of household and government constraint yields an income-expenditure statement in real terms.

A steady-state solution for all the relevant variables is easily satisfied under mixed bond-money financing. The steady-state condition requires that both money and bonds rise by equal percentages in this case. The deficit is, moreover, defined in the sense of the basic deficit exclusive of interest payments. Once the real deficit is fixed the associated percentage rise in nominal money balances determines the inflation rate. The optimality condition for real capital $k$ yields the optimal stock by equating its marginal product with the exogenous utility rate of time preference. Insertion of the latter result into the consolidated constraint yields the optimal rate of consumption. The remaining first-order conditions determine real balances, Lagrangian multiplier and equality between the real rate of interest and the utility rate of time preference. The latter follows from the occurrence of a positive bond stock. Lastly, the magnitude of this stock is settled by the real version of the government's budget constraint.

The solution of the mixed finance carries through without a hitch and also satisfies the transversatility conditions. Similarly, financing the deficit with money only poses no problem. The argument proceeds as above. This case implies, however, that the real rate of interest remains below the utiiity rate of time preference. A problem arises, however, when the deficit, as defined, is only financed by bond issues. The transversatile conditions are violated in this case. There thus exists no steady-state solution for bond-financed permanent deficit. We also note that the real version of the government budget constraint would imply a negative steady-state stock of bonds that cannot be reconciled with the model.

McCallum demonstrates that the problem is quite sensitive to the specification of the deficit to be held constant. The pattern changes once we move beyond the basic deficit and includes the interest service on the outstanding debt. The transversatility condition is not violated for the stock of bonds once this extended deficit measure is held constant. This reflects the fact that the growth of real debt per capita does not explode as in the case of a constant "basic deficit" but actually converges to zero. The difference in this case is that the persistent increase in interest pay- 
ments due to the rise in the stock of bonds is matched by corresponding increases in taxes. Last, McCallum establishes that a permanently noninflationary bond-financed deficit can occur, provided the growth rate of bonds is less than the utility rate of time preference. This implies that the basic deficit is negative and converges with time toward zero. The extended deficit remains, however, positive and converges to equality with the government's interest payments.

McCallum's analysis qualifies somewhat the central proposition advanced by Sargent and Wallace. A permanent deficit need not be inflationary and need not impose a change in the monetary regime. It depends partly on the nature of the policy rule specifying the permanent deficit. But McCallum's analysis still leaves unanswered a central issue in the Sargent-Wallace argument. We learn that a noninflationary bondfinanced basic deficit is impossible. It is impossible because the steadystate system cannot produce that result. This answer does not attend to the question of why, in reality, initial attempts at a noninflationary finance of a basic deficit are eventually doomed. A similar problem involves the other result, suspending the Sargent-Wallace proposition. The analysis describes a world of certainty, perfect foresight, and nondistortionary taxes. The real variables are not affected by noninflationary finance under the circumstances. It was argued in an earlier section that the prevalence of distortionary taxes with uncertainty about the incidence of future taxes very likely modifies substantially this picture of a bondfinanced permanent deficit. This case is reenforced by the remaining possibility that we live in a "non-Ricardian" world.

\subsection{The empirical relevance of the issue}

We still need to consider the relevance of the potential threat posed by a permanent large deficit to an anti-inflationary regime. The analysis offers by itself no evidence that an anti-inflationary policy executed in the present against a background of a permanent deficit policy cannot be maintained over the long run. A number of papers over the past years examined this issue. They investigated, in particular, whether persistent deficits eventually induced inflationary policies. Robert King and Charles Plosser (1985) offer for our purposes an excellent example of this literature. They first introduce some historical background and discuss the behavior characteristics of six different seignorage measures for the United States. They find that seignorage averaged over the period considered about three-tenths of 1 percent of gross national product. The various seignorage measures are also correlated for descriptive purposes with a range of important macro variables. The authors note here a 
correlation of .44 between the deficit and inflation over the postwar period.

However, it is worthwhile to note that the correlation is essentially zero (.02) for the 1929-1952 period. By way of contrast, there appears to be a positive correlation between money creation and both real and nominal deficits in the 1929-1952 period.

There is, in general, no evidence for a contemporaneous relation between deficit and money creation in the United States. The underlying analysis does not stress, however, any particular contemporaneous relation but essentially an intertemporal dynamic relation. "The empirical strategy, therefore, is to look for a dynamic relation between revenue from money creation and deficits." The crucial question is whether past deficits explain subsequent revenues from money creation. The statistical results show "that seignorage does not appear to make a significant contribution to predicting any of the other government policy variables." Even more noteworthy is that deficits do not help predict seignorage.

The study extends attention beyond the United States. Among the eight nations outside Latin America only Italy exhibits some significant contemporaneous correlation between national income account deficits and money creation. The four Latin American nations included show, in contrast, some significant contemporaneous correlation between these magnitudes. An investigation of dynamic intertemporal interrelation confirms, however, the results obtained for the United States. Switzerland forms an exception. This is somewhat surprising and makes, against the background of Swiss financial institutions, little systematic sense.

The study demonstrates that we so far possess little systematic evidence about the dynamic link between current fiscal policy and future monetary policy. The problem may have barely confronted Western nations over most of the postwar period. But the experience of Italy, Israel (Fischer 1984), and Argentina (Dutton 1971), and more casual observations from other nations does suggest that we should not rely on the persistence of the monetary regime observed over the sample period in a radically different fiscal context. The dynamic link emphasized by Sargent and Wallace hardly emerges in contexts of the modest deficits dominantly prevailing in the United States and some other nations until recently. The issue has thus just been opened, and King and Plosser offer a useful starting point for future explorations of the subject. But such explorations need to attend to a subtle but basic analytic issue. We encounter here a generalization of the problem faced in the old fiscalist debate. It is anything but clear how the relevant fiscal variables need be specified. In particular, it is not obvious that the official administrative deficit, the national 
income account deficit, or some real versions of these measures form the relevant magnitude for the analysis of our problem. Kotlikoff (1984) raised some searching questions about the standard measures of deficits. These questions extend to the analysis of any possible relation between budgetary operations and subsequent monetary regimes.

\subsection{The deficit and economic activity}

Traditional Keynesian and neo-Keynesian analysis suffered no doubt that lower income taxes or higher government expenditures raise economic activity. The presumed permanent inefficiency of the economy could be expected to offer a leverage for fiscal policy to influence output and employment. Recent experience with large deficits expected to persist into an indefinite future generated in the public arena increasing doubts about their beneficial effects. Analysis based on "non-Ricardian" assumptions emphasized, of course, for a long time the negative long-term effect of permanent deficits. These effects operate via the asset market on capital accumulation and normal output. Public doubts concentrate, however, for a variety of reasons on the short run effects associated with deficits. Voices emerged that argued that deficits actually exert a contractionary effect and lower output in the short run independent of further effects on normal output growth. Academia could hardly stay behind the new developments. The issue certainly deserves examination. Two papers are selected in order to probe the argument of "contractionary deficits" or "perverse fiscal policy."

Feldstein (1984a) recently explored the possibility of a "contractionary deficit." His analysis revives an argument widely used by Keynesians in the 1950s to explain in real terms a persistent inflationary drift. Prices are supposed to be asymmetrically responsive to positive and negative changes in demand. Allocative demand shocks are converted under the circumstances into a persistent inflationary drift. Sectors experiencing rising real demands raise prices by a substantial margin, whereas sectors exposed to shrinking real demand lower their price, at most, quite modestly. This idea is exploited by placing fiscal policy within an environment of specific interacting sectors. Feldstein initially presents a simple argument along the following line. Suppose income taxes are reduced. Consumption demand rises and investment falls. The latter follows from higher interest rates. Consumption goods prices rise, whereas investment goods prices remain unchanged. The increase in the price level against a constant velocity and money stock necessarily lowers the level of output. Lower taxes thus lower output.

This suggestive argument motivates a more general and explicit analysis based on the following summary structure: 


$$
\begin{gathered}
X=C_{h}+C_{g}+I_{h}+I_{g}, \\
\Pi_{c}(C) \cdot C+\Pi_{I}(I) \cdot I=v(r+\pi) \cdot M, \\
C=C_{h}+C_{g}, \quad I=I_{h}+I_{g},
\end{gathered}
$$

where $X=$ real income, $C=$ real total consumption composed of household consumption $C_{h}$ and government consumption $C_{g}, I=$ real total investment consisting of household investment $I_{h}$ and government investment $I_{g}, r=$ real rate of interest, $\Pi=$ expected rate of inflation, $M=$ money stock, $\Pi_{C}(C)=$ price level of consumption goods as a function of $C, \Pi_{I}(I)=$ price level of investment goods as a function of $I$, and $v=$ monetary velocity.

All variables in Eq. (34) occur in real terms. The simple addition of the components $C$ and $I$ in order to sum up to real income will not hold, in general, for a multisector specification with variable relative prices. Feldstein therefore postulates units for $C$ and $I$ that uniformly assure unit prices in the initial position.

Expression (35) states a quantity equation. The left side represents nominal income and the right side nominal demand. The structure is completed by introducing a consumption function and an investment function:

$$
C_{h}=\phi(X-T), \quad I_{h}=\psi(r) .
$$

$T$ refers to income taxes.

Expressions (34), (35), and (37) can be represented in a simple diagram. Line 1 in Figure 3.5. describes Eq. (34), and line 2 Eq. (35). The signs of the slopes are immediately established by inspection, and so are the directions of the shift induced by a reduction in taxes $T$. Both lines are shifted up, increasing the real rate of interest. The effect on real income remains ambiguous without additional constraints. Feldstein specifies three conditions sufficient to produce a shift of the intersection point to the northwest, as indicated in the graph. These conditions are (i) a lowinterest elasticity of monetary velocity, (ii) a large-interest elasticity of investment, (iii) a high elasticity of $\Pi$ with respect to $C$.

The formal exercise certainly produces the desired perverse fiscal policy. Its relevance remains, however, quite doubtful. The analysis appears strangely regressive at this time. Important price-theoretical contributions are disregarded, and we revert to a peculiarly ancient Keynesian world. Analytically more serious is a basic logical flaw. Movements along line 1 and of shifts in its position hold prices constant at unity by construction. Movements along line 2 and shifts in its position modify prices $\Pi_{C}$ and $\Pi_{1}$. Any shift of line $L$ along 2 thus modifies prices under the assump- 


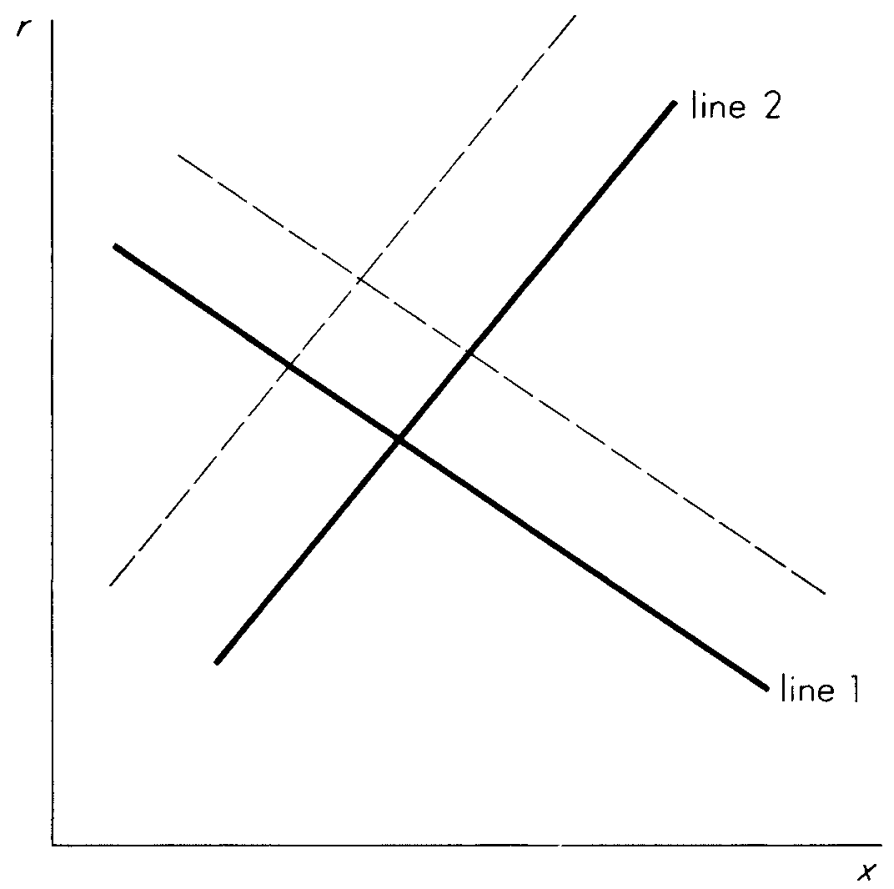

Figure 3.5

tions of unchanged prices. The same contradiction appears whenever line 2 is shifted along line 1 . A change in $T$ (or $C_{g}, I_{g}$ ) is thus analyzed within a framework exhibiting a flawed structure. This contradiction would seem to remove all significance from this attempt to establish a presumption for a "contractionary deficit."

Consider now an alternative procedure to move into a new world of fiscal policy analysis that reverses a long-accepted result of Keynesian analysis. Mankiw and Summers (1984) explored this possibility in the context of a slightly modified, but otherwise thoroughly standard, IS/LM analysis.

$$
\begin{gathered}
Y=C(Y-T, r)+I(Y, r)+G, \\
M=L(C, I, G, r) .
\end{gathered}
$$

The letters designating the relevant magnitudes assume their usual meaning. The modification applies to the money demand in Eq. (39). Money demand depends separately on the three expenditure components. Mankiw and Summers essentially concentrate on consumption $C$ as the 
relevant scale variable. The multiplier of income $Y$ with respect to $T$ is immediately determined as

$$
\frac{\partial Y}{\partial T}=\frac{C_{Y}\left[\left(L_{C}-L_{I}\right) I_{r}-L_{r}\right]}{\Delta},
$$

where $\Delta=-\left[1-C_{Y}-I_{Y}\right] \cdot\left[L_{I} \cdot I_{r}+L_{C} \cdot C_{r}+L_{r}\right]$

$$
-\left[I_{r}+C_{r}\right] \cdot\left[L_{C} \cdot C_{Y}+L_{I} \cdot I_{Y}\right]>0 \text {. }
$$

The detailed structure of the positive denominator $\Delta$ need not concern us here. It follows that the standard result holds according to the necessary and sufficient condition

$$
\frac{\partial Y}{\partial T}<0 \quad \text { iff } \quad L_{C}<L_{I}+\frac{L_{r}}{I_{r}}
$$

A necessary and sufficient condition for a "perverse response" can now be given as

$$
\frac{\partial Y}{\partial T}>0 \text { iff } \epsilon(L, C)>\left[\epsilon(L, I)+\frac{\epsilon(L, r)}{\epsilon(I, r)}\right] \frac{C}{I},
$$

where $\epsilon(y, x)$ denotes the elasticity of $y$ with respect to $x$. The major portion of the paper offers a valiant attempt to present a case for the crucial inequality yielding a positive tax multiplier. The discussion assumes that $L_{I}=L_{g}=0$.

The authors first assess with some rough calculations the crucial inequality. They assemble for this purpose available estimates and income account data. The results confirm the condition. Similar calculations suggest, moreover, that the expenditure multiplier is little affected by the change in specification. With a value less than one it is hardly a "multiplier," however. The tax multiplier, in contrast, changes sign.

A survey of the literature indicates to the author the superiority of permanent income or wealth as a scale variable. The permanent-income hypothesis of consumption suggests, under the circumstances, that consumption would offer a good proxy for the scale variable. The choice of consumption is further supported in the eyes of the authors by the ownership distribution of money. Measures comparing the variability of velocity derived from a variety of scale variables, and the results obtained from money demand regressions appear to offer more significant evidence in this context. The first difference of a consumption velocity based on $M 1$ exhibits the lowest variability. Similarly, the regressions assign, in 
general, a dominant weight to consumption compared to national income, disposable income and final sales, or total private spending as a scale variable.

The reservations about the traditional Keynesian tax policy are developed on the basis of a framework very close to those underlying the original fiscalist debate and judged to be unsatisfactory at the time by some Keynesian participants. Mankiw and Summers nevertheless raised a relevant point that may be robust beyond the simple IS/LM formulation used. An examination of the Brunner-Meltzer (1976) model reveal that the impact of a tax cut on income from human wealth is substantially attenuated by wealth and substitution effects on asset markets. A tax cut on income from nonhuman wealth produces a stronger response. The two tax cuts induce, moreover, opposite shifts between consumption and investment. These distinctions are glossed over by Mankiw and Summers and so are the substitution responses conditioned by distortionary taxes. Their explorations could be interpreted to mean that the short-run stabilization function of tax policies should be recognized as a questionable exercise. Comparatively much more important are long-run aspects of tax policies shaping the use and development of an economy's resources.

\subsection{The behavior of deficits}

With the beginning of this decade, fiscal policy and deficits became a major theme attracting public attention. Wall Street and the media assigned increasing importance to the deficit. There emerged a widening conviction that we entered a new era characterized by large permanent deficits. This conviction essentially suggests that the nature of the process determining the behavior of deficits in the United States substantially changed by the end of the 1970s. Such a change would reflect the emergence of a new pattern in the political process controlling the deficit. The occurrence of a structural break in policy regime cannot be excluded a priori. But our impressions of the past four years offer no relevant evidence in support of the thesis. In order to judge our situation we need a theory about the process controlling the deficit. Guided by such a theory, suitable tests yield some evidence on the thesis asserting the recent emergence of a new fiscal regime in the United States.

For most of the postwar period there was little reason to address this issue. Macro analysis thus neglected to develop a theory about the behavior of deficits. Barro's (1981a,b; 1984a,b) prolific contributions attend in recent years also to this dimension of fiscal policy. The basic idea guiding the research emphasizes that tax rates are essentially adjusted to perceived permanent government expenditures. Their response to perceived temporary changes in government expenditures remains, under the 
circumstances, quite modest. Tax revenues thus behave much more smoothly over time than actual government expenditures. A first study by Barro derives the tax-smoothing behavior from the government's optimizing behavior addressed to the minimization of the excess burden imposed by taxes on the economy. Bond-financed deficits associated with temporary bulges in government expenditures are thus designed to minimize the social cost of taxation. The specific simple theory elaborated in Barro's first study (1981a) actually implies that optimal tax policy sets a constant tax rate over time. This view was recently contested by Feldstein (1984b). This argument emphasizes that we need to compare the social cost of changes in tax rates adjusted to finance transitory bulges in government expenditures with the social costs of smaller but permanent tax rate increases needed to finance the additional interest payments resulting from the prior bond financing. An incorporation of plausible parameter values into this analysis suggests that tax financing of temporary government expenditures is superior to debt financing, provided the economy's stock of real capital is smaller than its optimal magnitude. Feldstein emphasizes, moreover, that in the case of permanent expenditure there exists essentially no financial choice. One way or the other these expenditures are covered by taxes. This analysis seems to imply that the optimal stock of public debt is zero.

Feldstein's analysis obviously cannot provide the starting point for an empirical analysis of deficits and public debt even if we accept its relevance as a benchmark for a welfare analysis of budgetary operations. Any positive interpretation of the essentially normative analysis is, moreover, immediately disconfirmed by the facts. Lastly; an evaluation of the normative analysis as a benchmark for welfare statements lies beyond the range addressed in this paper. But its normative relevance does not preclude that intertemporal tax smoothing may offer a good basis for an analysis of deficit behavior. This smoothing pattern may be explained very differently from Barro's initial formulation that was questioned by Feldstein. It thus seems quite appropriate that Barro simply postulates a tax-smoothing pattern in his most recent examination. This hypothesis is actually formulated in its most rigid form as a constant tax rate. The basic idea is, however, consistent with some contingent flexibility of tax rates over time.

The hypothesis to be tested is constituted by two building blocks. The first introduces the tax-smoothing hypothesis, and the second combines it with the specification of deficit in terms of the budget constraint. The tax-smoothing hypothesis is applied to an intertemporal budget constraint in order to determine the expected constant tax rate. This constraint is

$$
\int_{0}^{\infty} g(t) e^{-r t} d t+b(0)=\int_{0}^{\infty} \tau(t) y(t) e^{-r t} d t,
$$


where $g(t)$ designates real government expenditures, $b$ the inherited stock of real debt, $\tau$ the tax rate, and $y(t)$ the portion of income forming the tax base. Equation (42) immediately implies the condition for a constant tax rate:

$$
\tau=\frac{\int_{0}^{\infty} g(t) e^{-r t} d t+b(0)}{\int_{0}^{\infty} y(t) e^{-r t} d t}
$$

This condition can be transformed to yield a statement relating the tax rate with permanent government expenditures $g^{*}$ and permanent income $Y^{*}$. These permanent levels perceived at the intitial time $t=0$ involve two assumptions. The first specifies a trend growth rate $n$ for $g$ and $y$ such that the present value of $g$ (or $y$ ) along the trend equals the present value of the actual future course of $g$ (or $y$ ). We thus obtain

$$
\int_{0}^{\infty} g(0) \cdot e^{-(r-n)^{t}} d t=\int_{0}^{\infty} g(t) e^{-r t} d t
$$

and a similar expression for $y$. Secondly, the permanent levels $g^{*}$ (and $y^{*}$ ) are then defined by the condition

$$
\begin{aligned}
& g^{*}(0)=(r-n) \int_{0}^{\infty} g(t) e^{-r t} d t, \\
& y^{*}(0)=(r-n) \int_{0}^{\infty} y(t) e^{-r t} d t .
\end{aligned}
$$

This condition establishes a relation between the present value of $g(t)$ (or $y(t))$ and its permanent level of $g$. A suitable replacement in expression (42) yields the desired relation between the average tax rate $\tau$ and the permanent magnitudes

$$
\tau=\frac{g^{*}+(r-n) b(0)}{y^{*}}
$$

The second building block invokes the budget constraint expressed in real terms

$$
\frac{d b}{d t}=g+r b-\tau y
$$

where $b$ represents the stock of real debt. Replacing $\tau$ in (47) with the aid of (46) and rearranging terms yields the basic relation

$$
\frac{d b}{d t}=\left[1-\frac{y}{y^{*}}\right]\left[g^{*}+(r-n) b\right]+\left(g-g^{*}\right)+n b .
$$


The first term describes a cyclical effect. The deficit increases during recession and recedes during upswings. The effect of the business cycle on the deficit increases, moreover, with $g^{*}$. The second term-that is, $(r-n) b$-within the bracket is negligible and can be disregarded. The second term indicates that temporary government expenditures affect the deficit one for one. Lastly, the third term reflects the financing of interest payments on outstanding debt made possible by the "normal growth" in debt corresponding to the trend growth of the economy. This item unavoidably occurs once we assume a constant tax rate. Otherwise the relative interest burden would fall and tax rates could not be constant.

Equation (48) describes the growth of real debt as of any path of the price level. It follows that multiplying both sides of Eq. (48) with the price variable does not adequately render the growth of nominally valued debt $B$. The expression $\pi B$ multiplying the inflation rate with the stock $B$ must be added. We thus obtain

$$
\frac{d B}{d t}=(n+\pi) B+\left(1-\frac{y}{y^{*}}\right) P g^{*}+P\left(g-g^{*}\right) .
$$

One more term must be added, however. The structure of this last term depends on whether the debt variable is measured at market or at par value. In either case the dependent variable is modified over time whenever the average market rate of interest changes.

The underlying analysis ultimately yields the following regression:

$$
\begin{aligned}
& \frac{B_{t}-B_{t-1}}{P_{t} Y_{c}}=a_{0} \frac{B_{t-1}}{P_{t-1} Y_{t-1}}+a_{1} \pi_{t} \frac{B_{t-1}}{P_{t-1} Y_{t-1}} \\
& +a_{2} \text { YVAR }+a_{3} \text { GVAR }+a_{4} \text { RVAR }+U_{c} .
\end{aligned}
$$

YVAR refers either to $\left(1-y / y^{*}\right)\left(g^{*} / y_{t}\right)$ or to an expression based on the unemployment rate related to the first by a modified "Okun's law." Either formulation reflects the cyclic influence on the deficit. GVAR expresses the temporary government expenditures, and RVAR the adjustment required to reflect the effect of changes in interest rates on market or par value of debt $B$. The hypothesis summarized by Eq. (50) implies that

$$
a_{0}=n \quad \text { and } \quad a_{1}=a_{2}=a_{3}=1 .
$$

An extensive range of empirical examinations substantially confirms the component $a_{1}=1$ of the total hypothesis. The confirmation holds for the whole sample 1920-82, for the sample without the war, and subsamples $1920-40$ or 1950-82. The coefficient $a_{3}$ on temporary government expen- 
ditures lies between .5 and .6 for the whole sample and drops to .22 whenever the war data are deleted. The results from the subsamples confirm this pattern. The largest estimate is .16. Two estimates out of 12 are (nonsignificantly) negative, and ten are smaller than their respective standard error. We observe here no confirmation of the hypothesis. All estimates of $a_{3}$ are very significantly below unity. The "cyclic coefficient" $a_{2}$, in contrast, is uniformly positive and highly significant for all estimation periods and choices of YVAR. The coefficient estimate, however, occurs systematically on the high side. It clusters around 1.5. This result is not consistent with the strict tax smoothing hypothesis. It reveals a measure of cyclical flexibility in tax rates. Lastly, the estimate of $a_{0}$ appears to be persistently too low as an estimate of the trend growth in real GNP.

The regression analysis so far yields no evidence that the current decade ushered in a new regime of budgetary processes. The observations on the deficit cast up by the four years 1980-83 are quite compatible with the patterns observed in past years. The estimated deficit traces the actual value quite well, and the residuals remain in the usual range. The regression even overpredicts the deficit for three out of four years. Barro's results also imply that realization of the CBO's baseline projections over the next five years would indicate a break in the structure of the process generating deficits. We would then actually have moved into a new policy regime. An unchanged policy regime would require substantial adjustments in expenditures and tax revenues in order to stay below the CBO projections.

The estimates of the coefficients associated with temporary government expenditures confront us with a serious and frequently occurring problem associated with the evaluation of hypotheses. Approximation errors in the measurement of specific variables may burden the statistical work with an uncertain interpretation. It is, in the present context, quite likely that the measurement of temporary government expenditures contains a substantial and variable error margin. But we know, of course, that measurement errors in the regressor bias the coefficient estimates toward zero. This problem is worsened by the fact that the sample period 1920-82 contains a single major observation for temporary government expenditures offered by World War II. Small values and little variation in this variable over most of the sample period combined with a potentially significant measurement error obscure the message of the data. A discriminating evaluation is not possible under the circumstances. It is very difficult to decide whether the results bearing on $a_{3}$ summarized above should be interpreted as a rejection of the hypothesis $\left(a_{3}=1\right)$ or can be reconciled with the hypothesis on the basis of the data problems indicated. A possible strategy to further explore the matter involves a search for data with more "action" and experimenting with different approaches to the measurement 
of theoretical entities as, for instance, in this case, the $g^{*}$ variable. Barro (1985) examined these opportunities with another paper exploiting British data for the period 1730-1918. These data exhibit much more variation in temporary government expenditures produced by military spending. The statistical investigation deletes the cyclic component. No reliable data seem to be available for this magnitude. This omission may partly explain the serial correlations of the regression residual. The regression estimated was confined to the two terms

$$
\frac{B_{t}-B_{t-1}}{P_{t} Y_{t}}=a_{0} \frac{B_{t-1}}{P_{t-1} Y_{t-1}}+a_{1} \hat{g}_{t}+w_{t},
$$

where $\hat{g}_{t}$ denotes temporary government expenditures, and $w$ a random term. The first term in this formulation summarizes the first two terms of Eq. (50). The hypothesis thus implies that $a_{0}$ is equal to the sum of trend growth $n$ plus the average inflation rate over the sample period 17551918. The estimate $a_{0}=.021$ coincides remarkably well with this sum. The estimate for $a_{1}$ moves, moreover, much closer to unity (i.e., $a_{1}=.9$ ) than in the case of the United States. This estimate is two standard errors from unity. The British data thus confirm the essential idea of the underlying hypothesis, but they do suggest some contingent tax adjustments.

The analysis of deficit behavior introduced a new dimension into macroanalysis. The public discussion erupting in recent years speculating about structural changes in our fiscal processes reveals the relevance of this emerging research. Barro deserves some credit for raising the issue in advance of the public arena's attention. The exploration of the "Ricardian theme" eventually led to an examination of deficits and public debt. We are hardly in a position at this stage to accept Barro's hypothesis with any sense of conviction. The evidence is still too unclear in this respect. But neither can we reject it. So far, it is "the only game in town."

\section{Concluding Remarks}

The professional discussion of fiscal policy has moved a long way over the past 20 years. The "great debate of the $1960 \mathrm{~s}$ " centered on the role of fiscal policy expressed by the effect of expenditures and taxes on national income and economic activity. This discussion did modify the earlier position of the postwar period represented by the works referred to in Section 2. There seemed also to ensue by the early 1970 s a consensus that fiscal policy did probably produce permanent nominal effects and temporary real macro effects. There remained substantial controversy about magnitude and temporal patterns of the consequences. There also persisted a 
basic disagreement about the role of fiscal operations in a concept of stabilization policy. An activist exploitation of fiscal instruments for purposes of short-run stabilization was typically advocated by the Keynesians. This contrasts with a more classical conception advocated by scholars with a monetarist and neoclassical view. This view rejects short-run manipulations and advocates policies addressed to the establishment of an institutional framework, not to sequences of fiscal actions. Such an "institutional policy" should provide an essentially confined, and thus reliably predictable, pattern of fiscal operations. This issue will be considered in the last paragraphs.

The temptation to sneer at the empirical work executed at the time seems, on occasion, irresistible. It would indeed be pointless to reproduce such investigations today. It would also express some measure of incompetence relative to the state of current economic and statistical analysis. But this work had a function at the time and was not irrelevant with respect to a strong thrust embedded in the Keynesian message. It did contribute to modifying positions even when not explicitly acknowledged. Modigliani's presidential address to the American Economic Association (1977) had a different flavor than the Keynesian stories of the 1950s. We note on the other side at least some monetarists with a more explicit recognition of fiscal variables than before. An unpalatable fact found, however, little resonance at the time. The central (non-price-theoretic) emphasis assigned in Keynesian analysis to income-expenditure flows made it quite sensitive to the choice of "autonomous expenditures." This choice seems anything but settled. The meaning of traditional Keynesian theory, on an empirical level beyond formal classroom exercises, remains obscure.

More recent discussions of fiscal impact on the macro behavior of the economy may usefully lead us beyond this impasse. The market or coordination failure conception underlying the Keynesian approach naturally produced an analysis downplaying the role of prices with an emphasis on interacting income-expenditure flows. The classic tradition rejects the basic failure conception motivating Keynesian analysis. A framework emphasizing a system of ("multiplying") interacting flows is thus replaced with an essentially price-theoretical conception. This conception should not be identified, however, with a (total) market-clearing analysis. The price-theoretical approach developed by Barro includes, moreover, the important distinction between anticipated and unanticipated fiscal events or, most particularly, recognizes the differential impact of temporary and permanent fiscal actions. The multiplier effect essentially vanishes in this price-theoretical context. The consequences of fiscal events, moreover, depend crucially on the government sector's use of the goods and services acquired from the private sector. Once we abandon the sinkhole theory, 
new channels of influence are recognized. Barro's analysis shows, for instance, that the impact of government expenditures on goods and services depends significantly on their "supply-side effects." This differs radically from the "demand-side dominance" of Keynesian analysis. This analytic evolution, initially suggested by Martin Bailey, still needs further elaboration. The operation of the government sector involves more than a pure redirection of privately produced goods within the private sector. It should be recognized as a production sector absorbing inputs converted into an output. The difference in the incentive structure between private and public sectors implies an important difference between the production functions of the two sectors. We also need to consider to which extent these consequences associated with the government sector as a production sector bear more significantly on longer-term aspects of an economy.

The dimensions covered by fiscal policy were significantly extended with the introduction of the Ricardian theme. The "Ricardian equivalence theorem" defines a useful benchmark for our professional discussions. It obliges the advocates of a more or less "conventional thesis" to specify the conditions responsible for the real consequences of the government's decisions how to finance expenditures. The possible recognition of a pure debt effect on real variables, explicitly acknowledged by the "stability analysis" of the early 1970s, would hardly suffice today. The discussion unleashed over the years directed our attention to new mechanisms or channels of influence conveying real impulses from the government's financial decisions. The association of deficit finance with intergenerational transfers, the role of uncertainty and risk related with future tax liabilities, and the condition of intergenerational transfers linked with the function of bequests deserve critical exploration by the profession. We may yet convince ourselves that the government's "financial mix" does exert some real consequences but, to some extent, for reasons beyond the pure debt effect. We also note that the extension of fiscal analysis summarized above increasingly directs our attention to a range of influences modifying the division of total output between real consumption, household real capital, and real capital used in the production process. These channels condition normal output. Their operation may be more important than the immediate impact on total output.

The emergence of an apparently persistent deficit was bound to attract the profession's interest. Attempts to justify some public concern that "deficits are contractionary" are so far at best speculatively "interesting." More significant seems to be the attempt to explain the observable behavior of deficits. A useful explanation would offer a criterion for judging the occurrence of changes in fiscal regime. The issue raised by Sargent and Wallace also deserves serious further attention. It involves a basic question about the political role of monetary and fiscal institutions 
and the relevant deficit measure guiding policy. The problem arises whenever fiscal institutions dominate the monetary institutions over the longer horizon. Political economy analysis seems to support this assumption. It follows under the circumstances that a breakdown of the "Victorian rule" (Buchanan 1985) ultimately determines an inflationary adjustment of monetary policy. The nature of the monetary regime ultimately depends on the prevailing fiscal regime. A noninflationary monetary regime thus requires for its survival a fiscal regime approximating a 'Victorian rule." But the analysis of this issue remained somewhat incomplete. The economic and political mechanism creating the accommodation of monetary policy to a permanent deficit still requires some attention. The empirical relevance is also unresolved at this time. There so far exists little supportive evidence, but then we may have only entered the age of permanent deficits.

Finally, a basic issue of political economy should be faced. The contrasting conceptions of fiscal policy offered by the Keynesian vision and the classical tradition were characterized in a previous paragraph. The issue cannot be left unattended with the easy escape into "ideology." There is more involved that deserves the careful attention of the political economist.

Three substantive issues condition the policy conception: the basic coordination failure of a market economy, the information problem confronting policymakers, and the characteristic operation of political institutions. Some Keynesians emphasize that the basic coordination failure of market economies necessitates the intervention of the government in order to offset this failure. Such intervention exploits to a large extent the powers of fiscal policy. The coordination failure to be corrected with the aid of fiscal policy involves, moreover, both a short-run and a long-run dimension. The latter dominated the attention at the end of World War II with the projections of oversaving and secular stagnation. This "structural coordination failure" justifies a permanent large deficit to offset private oversaving. This portion of the Keynesian argument offers no basis for activist manipulation of fiscal policy or for a large government sector. Activist manipulation follows from an emphasis of a "dynamic coordination failure" that produces inefficient fluctuations in output and employment.

One strand of the issue thus depends on the substantive question of a long-run (structural) coordination problem. The view advanced by Keynesians in this respect forty years ago was thoroughly disconfirmed by the end of the 1950s. The issue remains, however, as we still encounter assertions that an economy may be trapped within a set of multiple "underemployment equilibria." The other strand, represented by the "dynamic coordination failure," constituting the case for an activist fiscal 
policy, involves three distinct substantive issues. We note first the idea that fluctuations in output and employment are inherently inefficient. The reviving interest in "real business cycle theories" warns us, however, that economic fluctuations are not necessarily inefficient. The analysis developed by Stulz and Wasserfallen (1985) demonstrates, moreover, that economic fluctuations may reflect the characteristics of financial regimes. But this cautionary note is really just a special case of the general information problem faced by policymakers. The activist argument implicitly assumes that policymakers do possess reliable and detailed knowledge about the dynamic properties of the economy. Such knowledge would certainly allow the pursuit of an effective fiscal intervention. But such knowledge, while necessary, is not a sufficient condition for socially successful fiscal activism. We still need to invoke a goodwill or publicinterest theory or benevolent dictator view of government. The case for fiscal activism, at least for purposes of stabilization policy, thus involves two important empirical assumptions bearing on required information and the behavior of man in political contexts. The case for an "institutional policy" rests, in contrast, on the empirical proposition that the two crucial conditions postulated by advocates of activism do not hold in reality. We lack the needed detailed and reliable knowledge about the economy's dynamic structure. The range of analytic results and empirical positions covered in the survey demonstrates this state most explicitly. The consequences of this information problem are reenforced by the fact that self-interested behavior also permeates the political environment. There is little evidence that political agencies operate according to a generally recognized social welfare function. Fiscal activism produces, under the circumstances, more problems. We have no assurance that it will not generate truly inefficient fluctuations. These issues associated with the political economy of fiscal policy are wide open and far from settled at this stage. We may yet achieve some cognitive progress in this field once we recognize the substantive nature of the problems behind the ideological smoke.

\section{References}

Ando, A. and F. Modigliani. 1965. The relative stability of monetary velocity and the investment multiplier. American Economic Review 55: 696-728.

1976. Impacts of fiscal actions on aggregate income and the monetarist controversy: Theory and evidence. In Monetarism, ed. J.L. Stein. Amsterdam: North-Holland.

Andersen, L.C. and J.L. Jordan. 1968. Monetary and fiscal actions: A test of their relative importance in economic stabilization. Federal Reserve Bank of St. Louis Review 50: 11-24.

Aschauer, D. 1985. Fiscal Policy and Aggregate Demand. American Economic Review 75: 117-27. 
Aschauer, D. and J. Greenwood. 1985. Macroeconomic effects of fiscal policy. In Carnegie-Rochester Conference Series on Public Policy, Vol. 23. Forthcoming.

Baghat, S. and L.M. Wakeman. 1983. Non-diversifiable inflation risk and expected treasury bill returns. Working paper, University of Rochester, Rochester, New York.

Bailey, M.J. 1971. National Income and the Price Level. New York: McGraw-Hill.

Baltensperger, Ernst. 1984. The public debt: Limits and effects. Working paper, University of Bern, Bern, Switzerland.

Barro, R.J. (1978). The impact of social security on private saving: Evidence from the U.S. time series. American Enterprise Institute, pp. 1-36.

1981a. Money, Expectations, and Business Cycles: Essays in Macroeconomics. New York: Academic Press.

1981b. Output effects of government purchases. Journal of Political Economy 89: 1086-1121.

1984a. Macroeconomics. New York: Wiley.

1984b. U.S. deficits since World War I. Working paper, University of Rochester, Rochester, New York.

1985. Government spending, interest rates, prices and budget deficits in the

U.K. 1730-1918. Working Paper No. 1, Rochester Center for Economic Research, University of Rochester.

Barsky, R.B., N.G. Mankiw, and S.P. Zeldes. 1984. Ricardian consumers with Keynesian propensities. NBER Working Paper Series, No. 1400.

Bernheim, E.D., A. Schleifer, and L.H. Summers. 1985. Bequests as a means of payment. Journal of Political Economy. Forthcoming.

Blanchard, Olivier. 1984. Debt, deficits and finite horizons. NBER Working Paper Series.

Blinder, A.S. and R.M. Solow. 1974. The Economics of Public Finance. Washington, D.C.: Brookings Institute.

1976. Does fiscal policy still matter? A reply. Journal of Monetary Economics 2: $501-10$.

Bomhoff, E.J. 1983. Monetary Uncertainty. Amsterdam: North-Holland.

Boskin, M.J. and L.J. Kotlikoff. 1985. Public debt and U.S. saving: A new test of the neutrality hypothesis. Carnegie-Rochester Conference Series on Public Policy, Vol. 23. Forthcoming.

Brunner, K. 1951. Inconsistency and indeterminacy in classical economics. Econometrica, 19: 152- 73.

1970. Ein Neuformulierung der Quantitatstheorie des Geldes. Kredit und Kapital. 1-30.

1971. Survey of selected issues in monetary theory. Schweitzerische Zeutschrift fur Volkswirtschaft und Statistik 107 (1).

1976. Inflation, money and the role of fiscal arrangements: An analytical framework for the inflation problem. In The New Inflation and Monetary Policy, ed. M. Monti. New York: MacMillan.

Brunner, K. and A.H. Meltzer. 1972a. Money, debt and economic activity: An alternative approach. Journal of Political Economy 80: 951-77.

1972b. A monetarist framework for aggregate analysis. In Proceedings of the First Konstanzer Seminar on Monetary Theory and Monetary Policy, ed. K. Brunner. Berlin: Drunker and Humblot.

1976. An aggregative theory for a closed economy, and Reply. Monetarism: The principal issues: Areas of argument and the work remaining. In Monetarism, ed. J.L. Stein. Amsterdam: North-Holland. 
Buchanan, J. 1985. Budgetary bias and post-Keynesian politics. In Growth of Government, eds. A. Lindbeck and J. Myrman.

Buiter, W. and J. Tobin. 1978. Debt Neutrality: A Brief Review of Doctrine and Evidence. Manuscript.

Carlson, K. 1967. The federal budget and economic stabilization. Federal Reserve Bank of St. Louis Review 49: 5-12.

Chan, L.K.C. 1983. Uncertainty and the neutrality of government financing decisions. Journal of Monetary Economics 11: 351-72.

Christ, C.F. 1968. A simple macroeconomic model with a budget constraint. Journal of Political Economy 76: 53-67.

1979. On fiscal and monetary policies and the government budget constraint. American Economic Review 69: 526-38.

Darby, M.R. 1984. Some pleasant monetarist arithmetic. Federal Reserve Bank of Minneapolis Quarterly Review 8: 15-20.

DeLeeuw, F. and J. Kalchbrenner. 1969. Monetary and fiscal actions: A test of their relative importance in economic stabilization-A comment. Federal Reserve Bank of St. Louis Review 51: 6-11.

DePrano, M. and T. Mayer. 1965. Tests of the relative importance of autonomous expenditures and money. American Economic Review 55: 729-52.

Dutton, D. S. 1971. A model of self-generating inflation: The Argentine case. Journal of Money, Credit, and Banking 3: 245-62.

Evans, P. 1984. The effects on output of money growth and interest rate volatility in the United States. Journal of Political Economy 92: 204-22.

Feldstein, M. 1978. The impact of social security on private saving: Evidence from the U.S. time series: A Reply. American Enterprise Institute, 37-47. 1982. Government deficits and aggregate demand. Journal of Monetary Economics 9: 1-20.

1984a. Can an increased budget deficit be contractionary? NBER Working Paper Series.

1984b. Debt and taxes in the theory of public finance. NBER Working Paper Series.

Fischer, S. 1984. The economy of Israel. In Monetary and Fiscal Policies and Their Applications. In Carnegie-Rochester Conference Series on Public Policy, Vol. 20, 7-52.

Fischer, S. and R.C. Merton. 1984. Macroeconomics and finance: The role of the stock market. In Carnegie-Rochester Conference Series on Public Policy, Vol. 21, 57-108.

Friedman, M. 1952. Price, income, and monetary changes in three wartime periods. American Economic Review 42: 612-25.

Friedman, M. and D. Meiselman. 1963. The relative stability of monetary velocity and the investment multiplier in the United States, 1897-1958. In Stabilization Policies. Englewood Cliffs, N.J.: Prentice-Hall.

1965. Reply to Ando and Modigliani and to DePrano and Mayer. American Economic Review 55: 753-58.

Friedman, M. and A. Schwartz. 1963. A Monetary History of the United States 1867-1960. Princeton: Princeton University Press.

Goldfeld, S.M. and A.S. Blinder. 1972. Some implications of endogenous stabilization policy. Brookings Papers on Economic Activity 3: 585-644.

Grenander, V. 1954. On the estimation of regression coefficients in the case of an autocorrelated disturbance. Annals of Mathematical Statistics 25: 252-72.

Hall, R.E. 1978. Stochastic implications of the life cycle-permanent income hypothesis: Theory and evidence. Journal of Political Economy 86: 971-87. 

No. 720.

1981. Intertemporal substitution in consumption. NBER Working Paper

Hester, D.E. 1964. Keynes and the quantity theory: A comment on the Friedman-Meiselman CMC paper. Review of Economics and Statistics 45: 36468.

Infante, E.F. and J.L. Stein. 1976. Does fiscal policy matter? Journal of Monetary Economics 2: $473-500$.

Johnson, H.G. 1971. The Keynesian revolution and the monetary counterrevolution. American Economic Review 61: 1-14.

Keran, M. 1976. Monetary policy, balance of payments, and business cycles. Federal Reserve Bank of St. Louis Review 49: 7-17.

King, R.G. and C.I. Plosser. 1985. Money, deficits and inflation. In Understanding Monetary Regimes. Carnegie-Rochester Series on Public Policy, Vol. 22.

Kochin, L. 1974. Are future taxes anticipated by customers? Journal of Money, Credit, and Banking 6: 385-94.

Kormendi, R.C. 1983. Government debt, government spending and private sector behavior. American Economic Review 73: 954-1010.

Kotlikoff, L.J. 1984. Taxation and savings: A neo-classical perspective. Journal of Economic Literature 22: 4.

Lucas, R.E. 1984. Money in a theory of finance. In Essays on Macroeconomic Implications of Financial and Labor Markets and Political Process. CarnegieRochester Conference Series on Public Policy, Vol. 21, 9-45.

Mankiw, N.G. and L.H. Summers. 1984. Are tax cuts really expansionary? NBER Working Paper Series.

Mascaro, A. and A.H. Meltzer. 1983. Long- and short-term interest rates in a risky world. Journal of Monetary Economics 12: 485-518.

McCallum, B.T. 1981. Monetarist principals and the money stock growth rule. American Economic Review 71: 134-38.

1984. Are bond-financed deficits inflationary? A Ricardian analysis. Journal of Political Economy 92: 123-35.

Meese, R.A. and K.J. Singleton. 1982. On unit roots and the empirical modelling of exchange rates. Journal of Finance 57: 1029-35.

Meltzer, A.H. 1981. Keynes' general theory: A different perspective. Journal of Economic Literature 19: 34-64.

Meltzer, A.H. and S.F. Richard. 1985. Why the social security system is in crisis. Unpublished manuscript.

Miller, M.H. and C.W. Upton. 1974. Macroeconomics: A Neoclassical Introduction. Homewood, Ill.: Richard D. Irwin.

Modigliani, F.I. 1977. The monetarist controversy or, should we foresake stabilization policies? American Economic Review 67: 1-19.

Nelson, C.R. and C.I. Plosser. 1982. Trends and random walks in macroeconomic time series. Journal of Monetary Economics 10: 139-62.

Plosser, C.I. 1982. Government financing decisions and asset returns. Journal of Monetary Economics 9: 315-52.

1984. Money in a theory of finance. In Essays on Macroeconomic Implications of Financial and Labor Markets and Political Processes. CarnegieRochester Conference Series on Public Policy, Vol. 21, 47-55.

Plosser, C.I. and G.W. Schwert. 1978. Money, income and sunspots: Measuring economic relationships and the effects of differencing. Journal of Monetary Economics 4: 637-60.

Policies to Combat Depressions. 1956. A Conference of the Universities-National Bureau Committee for Economic Research. Princeton: Princeton University Press. 
Sargent, T.J. and N. Wallace. 1982. Some unpleasant monetarist arithmetic. Federal Reserve Bank of Minneapolis Quarterly Review 6: 1-17.

Seltzer, L.H. 1945. Is a rise in interest rates desirable or inevitable? American Economic Review 35.

Silber, W.L. 1970. Fiscal policy in IS-LM analysis: A correction. Journal of Money, Credit, and Banking 2: 461-72.

Stulz, R.M. and W. Wasserfallen. 1985. Macroeconomic time series, business cycles and macroeconomic policies. In Carnegie-Rochester Conference Series on Public Policy, Vol. 22.

Supplement to Review of Economics and Statistics. 1963. A Conference of the Universities-National Bureau Committee for Economic Research. Conference on Monetary Theory.

Tanner, J.E. 1970. Empirical evidence on the short-run real balance effect in Canada. Journal of Money, Credit, and Banking 2: 473-85.

Tinbergen, J. 1952. On the Theory of Economic Policy. Amsterdam: NorthHolland.

Tobin, J. 1980. Asset Accumulation and Economic Activity: Reflections on Contemporary Macroeconomic Theory. Chicago: University of Chicago Press.

1981. The monetarist counter-revolution today-An appraisal. Economic Journal 91: 29-42.

Wasserfallen, W. 1985. Makro okonomische Unterschuger mit Rationalen Erwartungen: Empirische Analysen fur die Schweitz. Habilitation thesis accepted by University of Bern. To be published.

Weil, P. 1984. Love thy children: Reflections on the Barro debt neutrality theorem. Harvard University Working Paper. 